\title{
MIGUEL AGUIRRE, IOSU ARAMBURU Y LA PROFESIONALIZACIÓN DEL ARTE CONTEMPORÁNEO EN LIMA (1997-2018)
}

\author{
Miguel Aguirre, Iosu Aramburu and the Professionalization of Contemporary Art \\ in Lima (1997-2018)
}

MIJAIL MITROVIC*

Fecha de recepción: 20 de diciembre de 2019 - Fecha de aprobación: 8 de junio de 2020

\section{Resumen}

El presente artículo examina las trayectorias profesionales de los artistas Miguel Aguirre y losu Aramburu desde la discusión de los procesos de profesionalización del quehacer artístico en Lima entre la década de 1990 y la actualidad. Desde una perspectiva etnográfica, que aborda sus biografías y los espacios de circulación de sus obras, así como los mecanismos de validación que el campo artístico y el mercado del arte contemporáneo han activado en las últimas décadas, el autor discute los procesos económicos y discursivos que permiten comprender la transformación de la noción de "arte contemporáneo" en Lima y las dinámicas institucionales (evaluación, exhibición, comercio, etc.) que esta instala hoy en la ciudad.

Palabras clave: arte contemporáneo; profesionalización del arte; mercado del arte; valor del arte.

\section{Abstract}

This article examines the professional careers of Peruvian artists Miguel Aguirre and losu Aramburu, discussing the processes of professionalization of artistic work in the city between the nineties and today. From an ethnographic perspective that approaches their biographies and the circulation spaces in the artworld, as well as the validation mechanisms that both the art field and the contemporary art market have activated in the last decades, the author discusses the economic and discursive processes that allow us to understand the transformation of the notion of "contemporary art" in Lima and the institutional dynamics (evaluation, exhibition, commerce, etc.) it installs in the city.

Keywords: contemporary art; professionalization of art; art market; art value.

* Mag. en Antropología. Docente de la Facultad de Arte y Diseño de la Pontificia Universidad Católica del Perú, Lima, Perú. Correo-e:m.mitrovic@pucp.edu.pe 


\section{Introducción}

En la imagen que actualmente proyectan muchos concursos de arte contemporáneo desaparece el mercado. De ese modo, el arte se nos presenta como algo inalienable y los concursos parecen determinar su valor en términos de la relevancia o la trascendencia, sin considerar la trayectoria comercial de los participantes. Frente a la percepción de que el mercado funciona hoy como un árbitro del arte (Graw, 2015), los concursos convocados por instituciones culturales públicas y privadas buscan la imparcialidad a través del saber experto. Con ello ponen en juego algo de esa mística del connaisseur, que mezcla la sensibilidad y el gusto bajo una figura de autoridad que se entiende a sí misma como ajena al mercado, inclusive como su opuesto (Price, 2001 [1989]). Pero, ¿qué sucede cuando las carreras artísticas profesionales -lo que implica competencia- encuentran en la obtención de un premio su despegue inicial? Dice Néstor García Canclini (2012 [2010]):

Los relatos de los jurados sobre los premios destacan [...] el difícil equilibrio entre los factores que influyen en la valoración. ¿Valoración de qué? Los premios se anuncian como si se otorgaran a una obra o a la carrera de un artista. Sin embargo, los jurados confiesan que consideran los antecedentes y la repercusión posterior en el mercado (los grandes premios suelen duplicar o triplicar los precios de las obras), la expectativa de los medios y el juicio que las comunidades de artistas, curadores, periodistas y directores de museos harán sobre los miembros del jurado por sus decisiones (p. 142).

Ciertamente, muchos premios de arte se nos presentan como formas de objetivar lo inalienable -el valor del arte- sin asumir su relación con el mercado, lo que supone un conveniente olvido de las consideraciones que García
Canclini destaca. Sin embargo, su planteamiento corre el riesgo de caer en una imagen demasiado estática que identifica directamente los premios con el mercado. Me interesa explorar este terreno a través de la exposición de las trayectorias profesionales de los artistas limeños Miguel Aguirre (Lima, 1973) y losu Aramburu (Lima, 1986). He reconstruido sus "carreras" a partir de conversaciones sostenidas en Lima durante la segunda mitad de 2018, además de información obtenida en archivos personales e institucionales y entrevistas con otras personas que, directa o indirectamente, participaron en sus redes de relaciones profesionales. Tras situarlos en un mínimo terreno histórico, discutiré sus trayectorias preguntándome por las transformaciones de la figura del artista profesional en Lima, además de los mecanismos de validación y valorización como los premios- que el campo y el mercado del arte han instalado en las últimas décadas en la ciudad. Así, paso a exponer algunas ideas sobre los premios de arte en Lima y la configuración institucional del arte contemporáneo desde fines de la década de 1990.

Según la periodización planteada por Giuliana Borea (2016), la primera etapa de la expansión del mercado de arte contemporáneo en Lima estuvo centrada en la institución de la Bienal (1997-2002), que funcionó como centro gravitacional de la escena. En ese contexto, la idea de la instalación, el video o la performance como formas "contemporáneas" del arte empieza a arraigar en la escena local, así como la figura del curador, aquel que indica la necesidad del discurso artístico para ese nuevo entorno institucional -el "arte contemporáneo"- que empezaba a configurarse en Lima. Ese período previo al boom del mercado, que empezó alrededor del año 2006, fue caracteri- 
zado por Villacorta y Hernández-Calvo (2002) como un momento donde la institución-arte se había expandido a través del aumento de galerías y espacios de exhibición, nuevas escuelas de arte y fotografía y la instauración de dos importantes concursos (Johnnie Walker y Patronato de Telefónica) que ofrecían premios de más de 10.000 dólares ${ }^{1}$. Al mismo tiempo, las reformas neoliberales de la dictadura de Alberto Fujimori habían promovido la llegada al país de una "cultura de consumo dirigida al grueso de la población -establecimientos de fast food, servicios de delivery, multicines, hogares conectados a la red, cabinas de internet, telefonía celular, televisión por cable-" (Villacorta \& Hernández-Calvo, 2002, p. 124), es decir, Lima sentía la llegada de la globalización.

Desde los años sesenta los premios de arte en esta ciudad estuvieron destinados principalmente a la pintura, y aumentaron entre las décadas de 1980 y 1990. Como sostiene Hernández-Calvo (2018), de dicho auge sobreviven hoy Pasaporte para un Artista -convocado por la Alianza Francesa, con más de veinte ediciones- y el Concurso de Pintura del Banco Central de Reserva del Perú -con once ediciones a la fecha-. En un texto escrito como parte de la organización de la primera edición del Premio de Arte Contemporáneo ICPNA, lanzado en 2018, Hernández-Calvo sostiene que estos estímulos existen

[...] de manera independiente al mercado. La importancia de esto debe resaltarse, porque virtualmente han desaparecido otros estímulos a la creación en nuestra escena, ahora claramente dominada por los aparatos de mercado. Si bien dicho dominio es un fenómeno global, en otras latitudes existen otros canales económicos para los artistas, además del mercado del arte (2018, p. 10, énfasis añadido).
Sin duda el campo del arte local no cuenta con la diversidad de estímulos públicos y privados que otras escenas ofrecen, pero me interesa recoger el "ahora" que el crítico ubica para diferenciar dos momentos: mientras que hoy claramente el arte contemporáneo se encontraría bajo el yugo del mercado, los concursos que en décadas previas dinamizaron la escena mantenían una relación distinta con el mercado, aunque la independencia no sea la mejor palabra para describirla.

En lo que sigue, haré énfasis en cómo las trayectorias de Miguel y losu permiten comprender los procesos de subjetivación de la figura del artista tal como se configuró en la escena local desde fines de los años noventa hasta la actualidad, para lo cual también hará falta que otros actores entren en escena, aunque no siempre con nombre propio. Habrá que pensar cómo esos procesos se desarrollaron al mismo tiempo que algunos museos, galerías y escuelas locales se insertaban en el "arte contemporáneo", entendido como una forma global que redefinió el arte como algo alejado de la trascendencia, la inalienabilidad y la figura del genio -centrales a los modernismos, según lo planteado por Daniel Miller (2001)-, mientras esos mismos valores continuaron reproduciéndose en el mercado. Este proceso ha generado bastante confusión en cuanto a lo que muchos imaginan que es el arte contemporáneo ahora.

\section{Miguel Aguirre y la emergencia del arte contemporáneo en Lima}

En una entrevista realizada poco después de recibir el primer lugar del Encuentro Nacional de Artes Visuales Trujillo 2017, ante una pregunta que suponía que el mercado estaba atrave- 
sando un momento dinámico, Miguel respondió: "No creo que el mercado artístico local esté atravesando un buen momento. Es más, todo indica que está casi paralizado desde inicios del 2016" (Paredes Laos, 2017). Aunque no dijo más sobre el mercado, lo citado fue suficiente para que el encabezado resaltase su parálisis.

Una de las explicaciones usuales a la ralentización del flujo de ventas en el mercado del arte es la inestabilidad política, de ahí que Miguel señalase la poca confianza que el gobierno de Pedro Pablo Kuczynski (2016-2018) generaba en la demanda de arte. Como lo sugiere Parodi Trece (2013), aunque la economía peruana haya mantenido el crecimiento después de la crisis global de 2008 ciertamente en menor proporción que entre 2002 y 2008, época del boom de las commodities-, la inestabilidad política ha desincentivado la inversión y la confianza en los negocios.
Lo mismo sucede con el mercado del arte: varias personas entrevistadas afirman que las peores épocas para vender son las elecciones nacionales y municipales. Por ello la firma de la "Hoja de ruta" de Ollanta Humala durante las presidenciales de 2011 significó un alivio para la inseguridad que corría durante la campaña entre los compradores de arte, como recuerdan algunos. No es casual que la Subasta de Verano del Museo de Arte de Lima (MALI) de aquel año haya sido una de las pocas ediciones en las que todo lo ofertado logró venderse, a diferencia de otras en las que muchas obras "pasaron"2. Es curioso que Miguel, tras ganar el premio con un proyecto sobre sus recuerdos de la crisis de los ochenta, terminara ubicado como portavoz de la sensación de parálisis del mercado del arte. Nada más lejos de su experiencia al presentar su primera exhibición individual en 1997 y de la imagen pública que entonces proyectó.

Figura 1. Miguel Aguirre, El hecho de que eres chica y él, hombre, óleo sobre tela, 124 x $90 \mathrm{~cm}, 1997$ (archivo del artista).

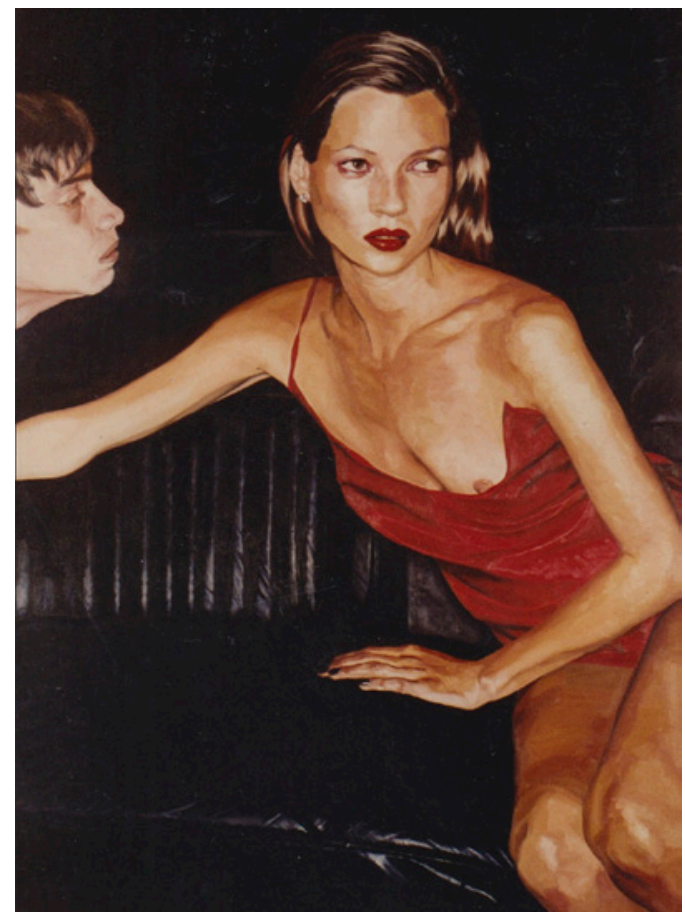


El joven que estira su cuello mientras es repelido por el brazo de Kate Moss es Miguel (Fig. 1). Tenía entonces 24 años y era común que apareciera en sus pinturas, a veces frente al espejo antes de lavarse los dientes, o tirado en el piso después de una borrachera. Pintaba otras cosas, pero sus autorretratos fueron las primeras obras que lo introdujeron en el imaginario del arte peruano de fines de los noventa. Historia gris del rojo amor (1997) fue su primera individual en la sala Luis Miró Quesada Garland de la municipalidad de Miraflores, y además de consolidar su relación con curadores como Villacorta, tuvo un impacto mediático difícilmente alcanzado por las muestras actuales en la ciudad. Además de vender varios cuadros, fue un "éxito en cuanto un público no necesariamente interesado en las artes visuales contemporáneas se enteró que yo existía"3. Según Carlos León-Xjiménez (1997), lo crucial de su propuesta era "[l]a exploración del yo, desde el amor propio, cuando la propia imagen es punto de partida para una confrontación" (p. 7B).

En la década de 1990 imperó en el arte limeño una "estética de lo subjetivo", primero en un tono introspectivo o autobiográfico que, una vez afirmado entre los artistas jóvenes, se topó con imágenes del consumo masivo y de la cultura global de la celebridad (Villacorta \& Hernández-Calvo, 2002; Del Valle \& Villacorta, 1997. La primera exhibición de Miguel es un hito de dichos desplazamientos, pero esa orientación hacia la cultura popular venía desde su adolescencia:

Admito que fui un privilegiado, un chico de clase media,
pero que, como todos en el Perú, se vio obligado a
hacer largas colas para conseguir pan, leche Enci o
kerosene [...] Casi no salía de casa y no tenía amigos
en el barrio. Política, social y económicamente estába-
mos en la ruina, y yo me refugiaba viendo la televisión
o escuchando radio (Paredes Laos, 2017).

Esa estética de lo subjetivo respondió a la clausura de cierta esfera pública en la que el arte participaba, sobre todo a través de la denuncia de la guerra, desarticulada tras el autogolpe de Fujimori de 1992 (Villacorta \& Hernández-Calvo, 2002; Mitrovic, 2019). La relación entre ambas etapas que hoy es posible advertir no aparece en los comentarios hechos en el momento de la exhibición de Miguel. Sus pinturas hablaban directamente a sus pares: "Siento que no necesito entender nada de ellas, sencillamente se conectan con cosas mías que incluso desconozco, y por tanto no puedo dar cuenta de ellas por medio de palabras", declara Ana Gabriela Alvarado en el folleto de la exhibición (Aguirre, 1997).

Figura 2. Miguel Aguirre, Lunes, óleo sobre tela, 125 × 190 cm, 1997 (archivo del artista).

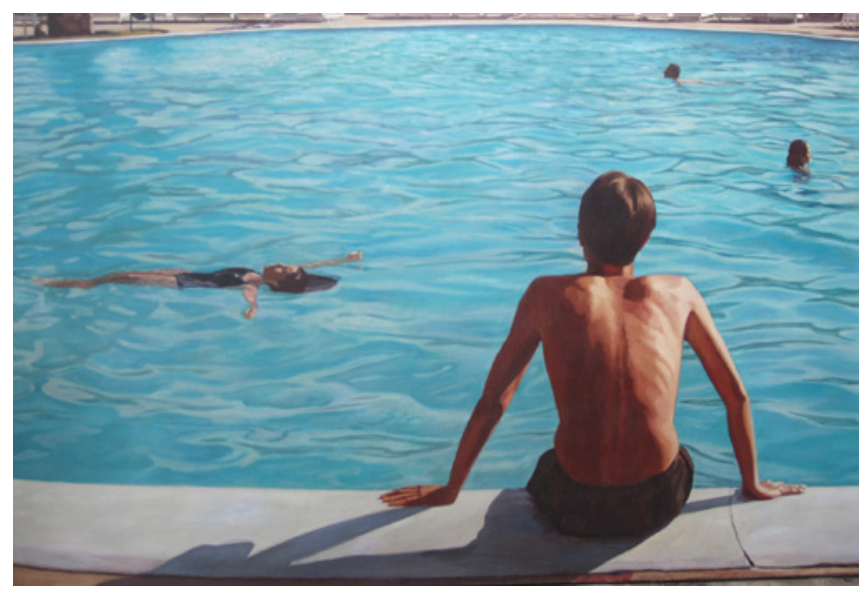


Sería legítimo preguntarse qué tiene que ver todo esto con el mercado del arte y la profesionalización que este empezó a impulsar desde entonces, pero, precisamente, la admiración provocada entre el público joven es lo que el mercado interpreta como una buena señal. Sin embargo, no es que la obra de Miguel haya ingresado al mercado recién al abrir la muestra: Lunes (Fig. 2), una pintura exhibida entonces, había sido vendida en su taller antes de ser terminada. Fue la primera vez que Miguel dejaba atrás los precios bajo los que vendió algunos cuadros mientras estudiaba en la universidad (entre 500 y 600 dólares), pues recibió 1.500 dólares sin tener que compartirlos con ninguna de las varias galerías con las que trabajaría luego ${ }^{4}$. Aunque aún no era representado comercialmente, ese era ya un "precio de mercado". Miguel piensa que "era demasiado joven en todo sentido. Tanto es así que me permitía el lujo de ser, por momentos, frívolo" y que aún no se pensaba como un artista que hoy busca cuestionar la realidad sociopolítica a través de su trabajo 5 .

En 1997 Miguel presentaba un perfil interesante para el mercado local: su propuesta era percibida socialmente como nueva y transgresora, parte de un sentir generacional. Al mismo tiempo, su obra podía articularse con un mercado en el que la pintura cargaba ya con una historia de coleccionismo de grandes artistas a los que podría suceder, además de una legitimidad social que excedía al propio mercado. A diferencia de los medios asociados a la "contemporaneización forzosa" del arte que Max Hernández-Calvo (2009) identificó como el principal efecto de las Bienales (la casi exigencia de asumir la instalación, el vídeo y la performance como los medios necesarios para "ser contemporáneo"), la obra de Miguel no suponía mayores problemas para concretar ventas, pues respondía, al mismo tiempo, a la incesante renovación de la representación pictórica y a la demanda de un medio ya asentado en el mercado (la pintura).

Lejos de las discusiones sobre qué es o no el arte contemporáneo, las primeras pinturas de Miguel decían claramente que lo suyo era representar la vida según la experimenta un joven de clase media que soportó la crisis de los ochenta gracias a la cultura de masas y que a fines de los noventa le daba una forma objetiva a algo que entendían sus pares y que el campo del arte empezaba a reconocer como contemporáneo. Después de esa exhibición, como recuerda alguien, "Miguel era un dios". Poco importa si lo era por las ventas o las notas de prensa, o ambas: reunía lo que entonces empezaba a asentarse en Lima como una figura ejemplar del artista exitoso bajo una forma distinta a la de los "maestros" del modernismo peruano.

Hacia la sociedad de consumo

Desde hace un buen tiempo el showroom de Wu Galería ofrece pinturas de Miguel, pese a que dejó de ser representado por ella hacia 2006. Para Frances Wu, Miguel fue una figura clave en un grupo de artistas jóvenes que apostó por "colocar" en el mercado6. Al montar en 1996 un taller de grabado donde editaba obra en serie de pintores modernos ya asentados en el mercado (Szyszlo, Llona, Wiesse, etc.), generó las bases para poner en marcha la galería en un local barranquino en 19987. Fue ella quien compró Lunes mientras Miguel aún la pintaba en su taller y ella también la que le puso el precio. 
Figura 3. Miguel Aguirre, Hortensia (dos veces) de la serie Los muertos, díptico, óleo sobre lienzo, 150 × $300 \mathrm{~cm}, 2001$ (archivo del artista).
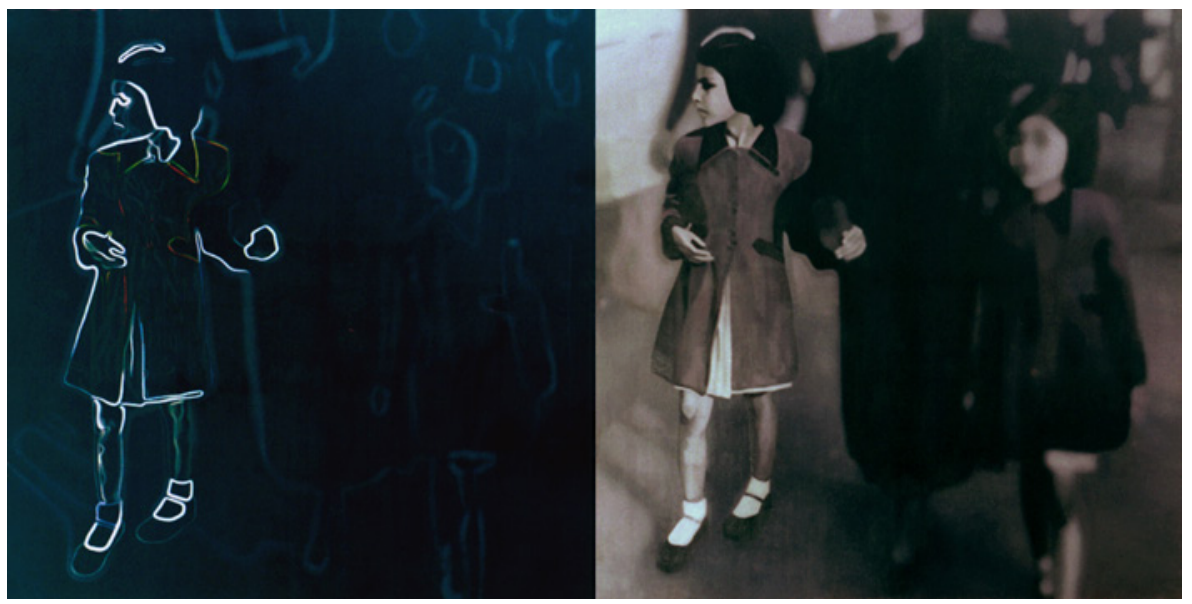

Desde 1999 Miguel trabajó con Wu y presentó cinco exhibiciones individuales en su galería hasta 2005. Según ella, vendió casi todo lo que expuso, usualmente a precios que tomaban como base el que ella misma había establecido al comprar Lunes años atrás. Aún el boom no empezaba y en 2001 Miguel partiría a España tras ganar el primer premio del $\mathrm{V}$ Concurso de Artes Plásticas Fundación Telefónica -un pasaje de avión y la beca de un año (20.000 dólares)- con la serie Los muertos (Fig. 3). Aquí Miguel emplea fotografías de sus familiares fallecidos como base para pinturas desenfo- cadas y sombrías. Pese a vivir fuera del país, su obra tenía una demanda consistente que se canalizaba a través de la galería. Hasta viajar a España su carrera había sido inusual para la escena local, pues era bastante joven y gozaba del reconocimiento tanto del público de a pie como del mercado, pero viajar y, sobre todo, vivir en el extranjero era entonces una aspiración entre los artistas limeños. "La plástica nacional espera muchísimo de él”, dice una nota de prensa, "su viaje será una experiencia inédita, él espera una revolución en su vida y en su arte" (Cárdenas, 2001). 
Figura 4. Nota sobre Naturaleza muerta, exhibición individual de Miguel Aguirre en Wu Galería, Expreso, 2003 (archivo Wu Galería).

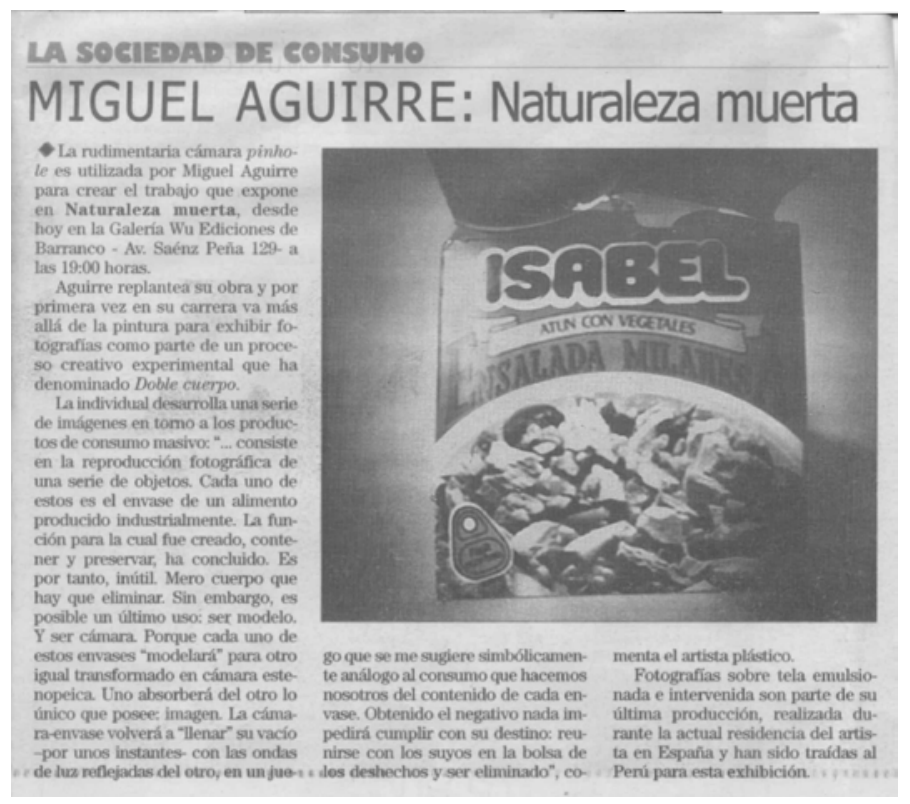

Tras la experiencia con Wu y aún en España, en 2006 Miguel empezó a trabajar con Lucía de la Puente (Lima), Espacio Líquido (Gijón), Pilar Serra (Madrid) e Y Gallery (Nueva York). Salvo por la primera, que ya cerró sus puertas, es aún representado por casi todas las galerías mencionadas, junto a la Galería del Paseo (Lima/Montevideo) desde inicios de 2018. En este segundo momento de su carrera, Miguel ya estaba establecido como un referente de la pintura local que también participaba en el mercado europeo. Su obra dejó atrás la centralidad que él mismo había tenido en sus cuadros -esa frivolidad de la que me habló- y su identificación con la cultura de masas pasó a disgregarse en una obra que mantenía su interés por las imágenes (fotografías familiares y de circulación masiva, por ejemplo), pero que establecía cierta distancia con la antes admirada globalización. En la exhibición Naturaleza muerta (2003), donde presentó Doble cuerpo, entre sus cámaras pinhole hechas de envases vacíos de productos industriales y sus propias imágenes espectrales ahora había lugar para conceptos como el de "sociedad de consumo" (Fig. 4). Ya no era el brazo extendido de Kate Moss el que alejaba sus impulsos. Él se había retirado de la escena.

Poco a poco se fue asentando en la escena limeña la idea de que los artistas que aspiran a ser contemporáneos deben tener un concepto y desarrollar proyectos, lo que relajó la exigencia modernista de que la obra hable "por sí sola", aún presente cuando Miguel expuso por primera vez. Junto a los cambios en su obra y discurso, hacia 2006 Miguel contaba con varias muestras y premios en Lima y España, y su cuádruple relación con galerías llevó a incrementar considerablemente sus precios: 
desde entonces, obras suyas cuatro veces más pequeñas que un cuadro como Lunes se ofertan en 1.500 dólares, mientras que sus cuadros de mayor formato oscilan entre 5.000 y 7.000 dólares (o el mismo número en euros, si se trata del mercado europeo), y a veces hasta 12.000. Los tejidos que hoy elabora con Elvia Páucar no bajan de 7.500 dólares y una serie de 28 pizarras se ofrece en 45.000. Para ese momento, Miguel trabajaba bajo el estándar internacional -que recién se establecería en Lima en 2013, el mismo año que se inauguraron las ferias ArtLima y PArC- en el que las galerías perciben $50 \%$ del precio de venta.

Conviene explorar el señalamiento de Raymonde Moulin (2012) sobre la relación entre las dimensiones estética y financiera que opera en el mercado del arte. Según la socióloga, el precio de una obra representa el lugar que un artista ha adquirido en el campo del arte a través del juicio de historiadores, curadores y críticos. Tras ratificar el valor mediante la venta, el precio pasa a circular socialmente esos juicios como su representante. Antes de concretarse la venta, el precio puede parecer excesivo, pero la transacción efectiva le da una especie de carácter evidente: si alguien ha pagado ese precio por una obra, entonces tiene valor y este corresponde con el precio: "El precio, una vez logrado en el mercado, facilita y acelera la circulación y la internacionalización del juicio estético" (2012, p. 35).

En ese sentido, entre 1997 y 2005 el valor de la obra de Miguel pasó de objetivarse alrededor de su propia figura, tal como aparecía en sus cuadros, notas de prensa, entrevistas y reconocimientos públicos, a desplazarse hacia las obras y sus precios, ahora acompañadas de discursos que hicieron que su obra pictórica y fotográfica forme parte del arte contemporáneo local. A nivel formal, esas eran las principales diferencias respecto de sus primeras pinturas que, si alguna crítica negativa habían recibido, era que no alcanzaban ninguna cohesión mayor que un "álbum de figuritas" sin un concepto unificador. Pese a ello, Miguel encarnaba una subjetividad socialmente reconocida como capaz de darle una forma objetiva a experiencias trascendentes (literalmente incomunicables, como leímos antes). Y esta subjetividad, ahora, ya podía desplazarse hacia nuevos rumbos. El incremento de sus precios en el mercado no hizo sino ratificar todo el proceso previo.

\section{Deseos diferenciados}

El desarrollo artístico de Miguel ha hecho que hoy sea percibido como un artista erudito que, según una galerista, "no es para las masas", pues reclama que se le sepa leer. Eso puede generar un escenario de venta complejo. A nivel profesional o inclusive personal, es visto por las galeristas como alguien claro en cuanto a sus movimientos en el mercado y el mundo del arte, además de responsable y preocupado por mantener un buen vínculo con las galerías. Para algunas galeristas eso se explica "porque vivió fuera", pues ha aprendido a valorar lo que ellas hacen por los artistas, en contraste con la informalidad que impera entre muchos artistas locales. Miguel no le "saca la vuelta" a su galería, según escuché, aunque la misma persona reconoció que uno se entera de esas cosas en tiempos de crisis, ya que el boom permite cierto relajamiento de la vigilancia sobre qué hace cada quien en el mercado.

Miguel estuvo fuera del país durante el boom del arte contemporáneo local que empezó hacia 
el año 2006 y no siempre tan holgado como lo proyecta la imagen de un artista exitoso. Sería útil interrogar la gran cantidad de pinturas por encargo que realizó para sostenerse mientras vivía en Barcelona desde la pregunta de cuántas de ellas responden a lo que entiende como su propuesta artística y cuántas satisfacen una demanda que no necesariamente está alineada con lo que considera su obra. Las segundas ganan por mucho a las primeras, según dice, y por ello forman parte de su trabajo, mas no de su obra, y es esta última la que interesa al mercado del arte.

Figura 5. Miguel Aguirre (en colaboración con Elvia Páucar), Políticas de lo psicosocial III. Tú, tú eres el imán y yo soy el metal / Me voy acercando y voy armando el plan, tejido en lana de oveja, $200 \times 138 \mathrm{~cm}$ aprox., 2018 (archivo del artista).

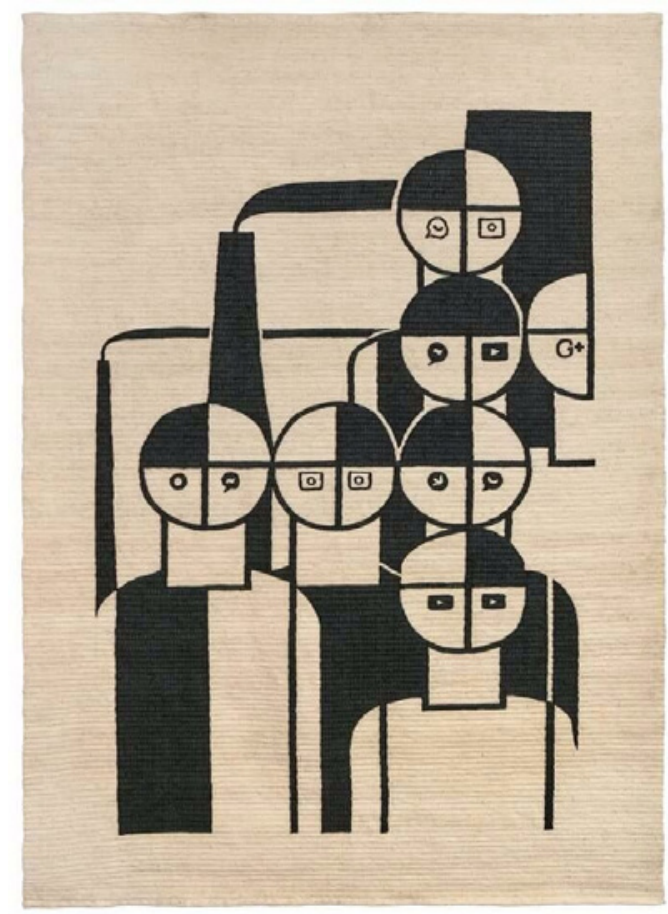

Al alejarme del tejido de Miguel (Fig. 5) veo que el booth de la Galería del Paseo en la feria PaRC 2018 (aún en el Museo de Arte Contemporáneo de Barranco) tiene una mesa donde se exhiben publicaciones de los artistas que representan. La obra quedó finalista en el primer Premio Arte Contemporáneo ICPNA y el catálogo está ahí para persuadir a posibles compradores, pues las galerías buscan que el precio de las obras se justifique a través de otros medios de expresión del valor. El tejido se vendió una vez terminada la feria, pero estuvo ahí, junto a muchas otras obras que esperaban recibir eso que, según el pensamiento económico hoy dominante, solo los ojos del deseo les pueden dar: valor. De ahí el esfuerzo que las 
galerías despliegan para hacer que unos pocos metros cuadrados se conviertan, por unos días, en espacios de exhibición, conversación y brindis donde la conexión íntima entre oferta y demanda pueda florecer. Desde luego, aquí se trata de una "teoría subjetiva del valor", que tiene sus bases históricas en la revolución marginalista del siglo XIX y que fue incorporada luego a la economía neoclásica (Roncaglia, 2016). Como comenta una guía de inversión local: "el negocio del arte va más allá de parámetros económicos y de inversión, puesto que una obra no tiene valor en sí misma sino que depende de la valoración que los diferentes actores del mercado -en particular el comprador- tengan de ella" (Semana Económica, 2014, p. 14).

Figura 6. Miguel Aguirre, Chinito del Ande, de la serie Miopía, acrílico sobre tela, $190 \times 150 \mathrm{~cm}, 2012$ (archivo del artista).

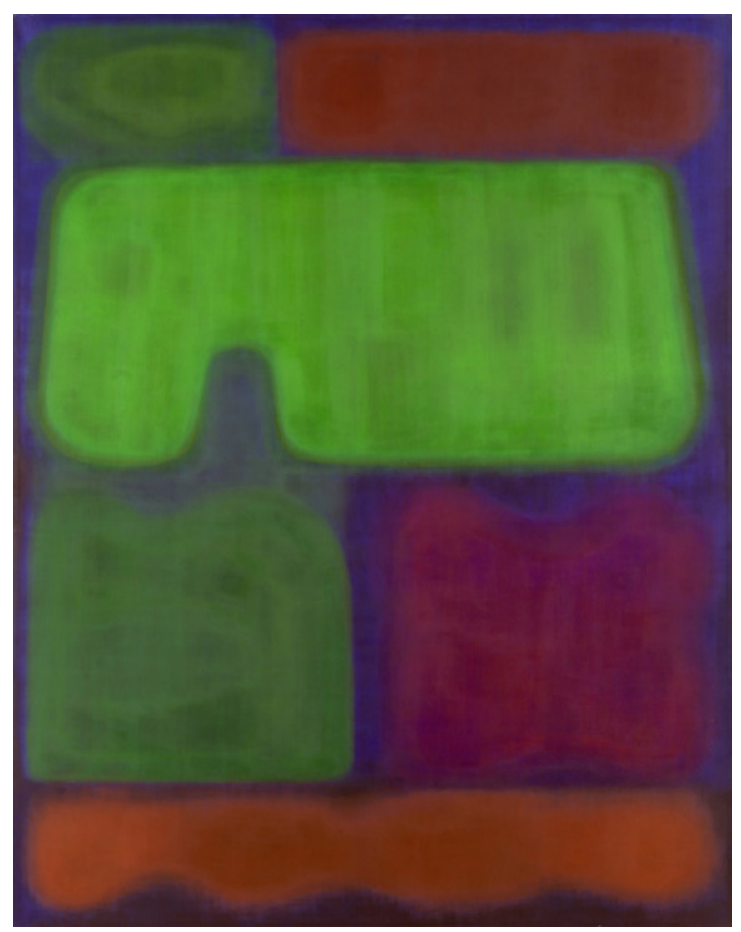

Los recientes tejidos de Miguel muestran que la cultura de masas ha sido el objeto de reflexión constante en su carrera. Junto al yo exacerbado de las celebridades, los objetos de consumo masivo y las imágenes de prensa hoy aparecen figuras de la cultura popular urbana limeña ${ }^{8}$. Después de conversar en su taller, salimos con Miguel hacia el Hotel B en Barranco, un negocio de la ex galerista Lucía de la Puente y su familia, en el que muchas obras de su colección se exhiben en los distintos espacios del hotel, en los que "las vibraciones contemporáneas se encuentran con la exuberancia fin de siècle" . Vibraciones es una buena palabra para describir el efecto que el cuadro de la serie Miopía (2012) (Fig. 6) genera al entrar al lobby, una abstracción que Miguel obtiene al quitarse los lentes ante un 
"afiche chicha". Curiosamente, sus tres obras, ubicadas en distintos espacios, comparten la cultura popular urbana como referente.

Al subir a una pequeña sala abarrotada de obras y libros coffee table sobre cultura peruana, advierto que un tejido de la serie Woven in Peru (2012) cuelga encima de una puerta (Fig. 7). Fue uno de los primeros tejidos que Miguel produjo al recibir una comisión por parte de Fraport-intermediada por Lucía de la Puente, su galerista entonces-, una enorme empresa alemana de logística aeroportuaria que buscaba arte para un espacio en el aeropuerto de Fráncfort. Fueron 45.000 euros por seis tejidos, por lo que Miguel estableció el precio unitario en 7.500 (euros o dólares), el mismo que hoy mantienen sus nuevos tejidos, aunque ahora no incluyen el costo del enmarcado ${ }^{10}$. Pero la obra de Miguel que ocupa un lugar especial en el hotel es, sin duda, Tipos de Lima (2011-2014) (Fig. 8), una serie de pequeños óleos sobre papel que retratan a trabajadores de la ciudad abstraídos del espacio que los circunda y donde Miguel ensaya una mirada de turista. El lugar especial en el que está esta serie es conocido como "la biblioteca" (Fig. 9), una sala en la que se sirve el tea time y donde puede compararse la obra de Miguel con un conjunto de acuarelas de Pancho Fierro.

Figura 7. El tejido de Miguel Aguirre en Hotel B (fotografía del autor).

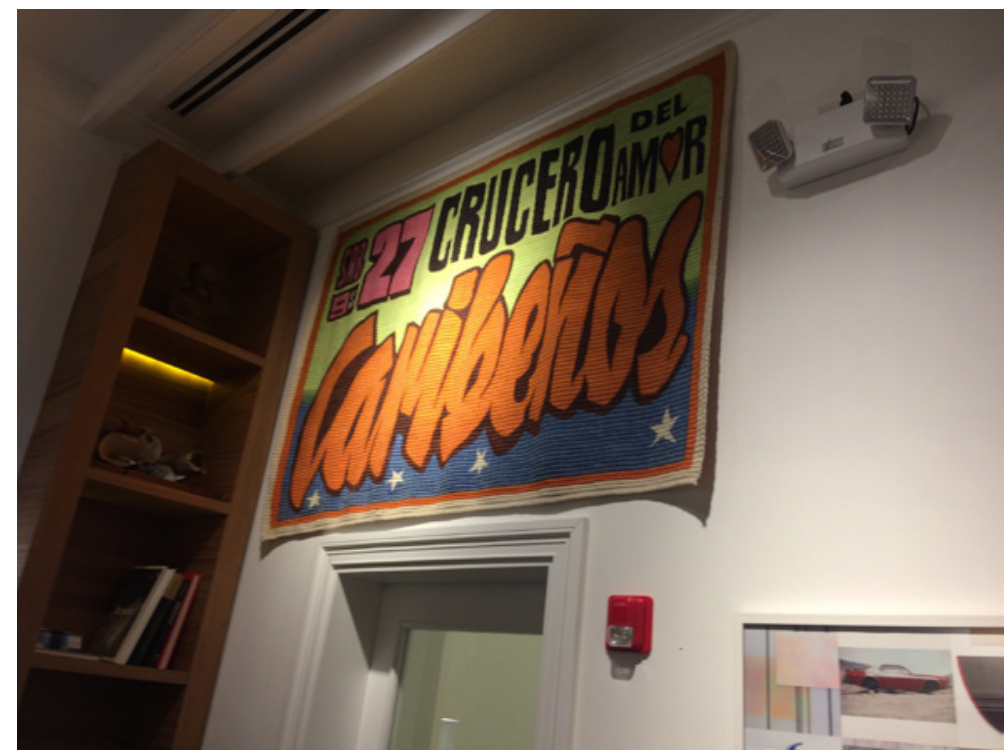


Figura 8. Miguel Aguirre, Vendedora de gaseosas, de la serie Tipos de Lima, óleo sobre papel de celulosa, 50 × $35 \mathrm{~cm}$, 2011-2014 (archivo del artista).

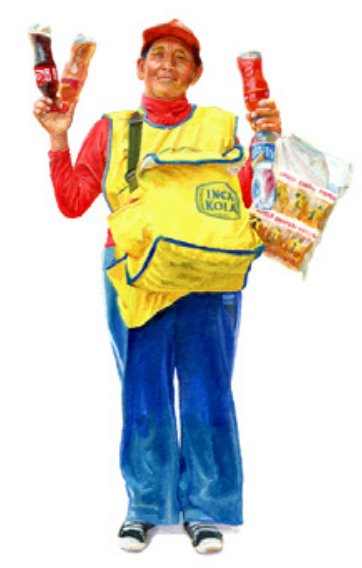

Figura 9. Pancho Fierro y Miguel Aguirre en "la biblioteca", Hotel B (fotografía del autor).

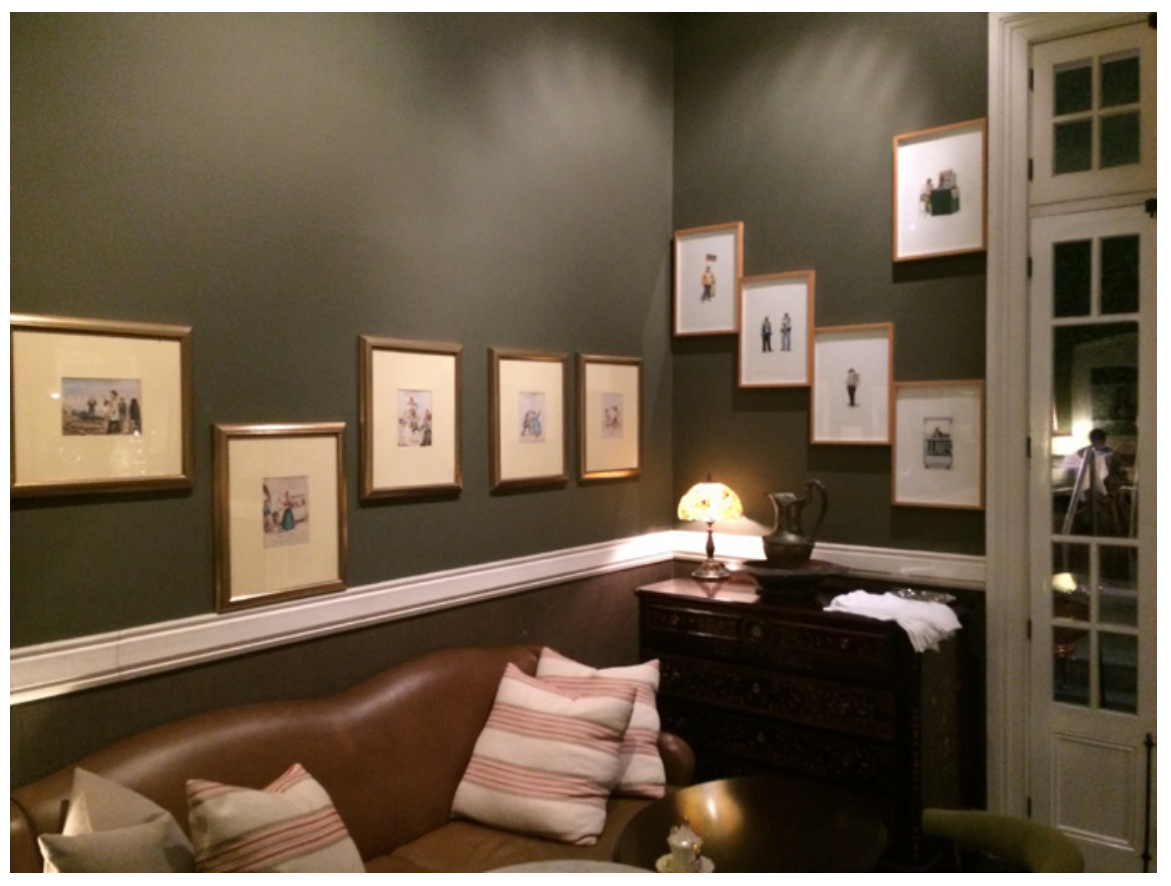


Los 23 Tipos que presentó en la muestra Lima, Limón, etc. (galería Lucía de la Puente, enero-febrero 2012) se vendieron rápidamente. Acordó los precios con Lucía en función de las horas de trabajo (cantidad de detalle) que le había requerido cada imagen: los precios iban desde 800 hasta 1.200 dólares. Algunas piezas fueron compradas por Eduardo Hochschild, quien ya había comprado en la galería varias pinturas de la serie Biopic"1. "Hochschild" fue el apellido del nuevo dueño que le comunicaron a Miguel tras la venta. No lo conocía, pero al visitar Lima hacia 2009 su nombre era invocado en las conversaciones con sus colegas. "Has más Tipos de Lima porque hay gente en espera". El telegrama iba desde Barranco hasta Barcelona, donde aún residía. Dos piezas del segundo grupo desfilaron por la VII Subasta de Verano del MALI (2013), con un precio base de 2.000 dólares por ambas. Usualmente el precio con el que empieza la puja es menor al estimado que aparece en el catálogo de la subasta, por lo que no extraña que se hayan vendido a ese mismo precio.

Es con el tercer grupo de Tipos producidos en 2014 que los precios se duplicarían en algunos casos, pues el mínimo subiría hasta 1.000 dólares por pieza y aquellas realmente trabajosas llegarían a 2.000. "Es la que mayor éxito ha tenido de todas mis series", dice Miguel, aunque la insistente demanda por más de tres años lo haga sentirse algo incómodo con que parecen haber sido producidas por encargo ${ }^{12}$. Le preocupa más el que hoy, pese al éxito, han terminado "siendo postales", como sugiere la centralidad que tienen en el espacio del hotel donde, semanas más tarde, me reuní con Lucía de la Puente a conversar. Para ella, esas piezas fueron más digeribles que otras más asentadas en la propia historia de la pintura o el cine. Los Tipos no requieren demasiadas preguntas sobre cuál es el "concepto detrás de la imagen" y, por ello, recuerda, había cola para comprarlas ${ }^{13}$.

Miopía también fue una serie exitosa. Un contraste interesante entre esa serie y los Tipos conecta sus respectivas formas de representar lo popular con su desempeño en el mercado. Mientras Miopía nos da una imagen borrosa que opaca el brillo de los colores exuberantes de los afiches chicha, los Tipos nos muestran personajes retratados por un "ojo de turista", como sugirió Lucía, que empataron bien con compradores locales que, como ella, los consideraron ideales para ver la imagen de una Lima que "ya no es gris". El grueso de los Tipos, sin embargo, se encuentra en colecciones privadas que no permiten entender los usos a los que están destinados hoy en día.

Miopía, al contrario, se vendió principalmente a extranjeros motivados por su cercanía con el expresionismo abstracto, según la galerista, por lo que importa menos la referencia local en esas transacciones. No es seguro que la demanda de los Tipos se explique por su posible utilidad como postales. Tal vez haya otros factores en juego, como los criterios bajo los que el mercado local se mueve: como sugirió un marchante, el de Lima es un mercado en el que las decisiones se toman por el nombre del artista, frente a otros mercados (norteamericanos y europeos, dijo) donde predominaría la calidad de la obra. Para el mercado local, los Tipos parecen encontrar el balance exacto entre un concepto fácilmente determinable y ciertos usos posibles como postales de la ciudad, todo ello amarrado bajo el nombre de Miguel. Además, no hay que olvidar que son pinturas y que cargan una larga historia de circulación comercial. 


\section{losu Aramburu y el boom del mercado del arte contemporáneo}

Al igual que Miguel, losu empezó a vender pinturas mientras estaba en la universidad, pero sus primeros vínculos con el mercado se hicieron efectivos hacia el año 2010, cuando terminó de estudiar pintura en la Pontificia Universidad Católica del Perú (PUCP) y conoció algunas personas que, más que fungir de marchantes, generaban vínculos comerciales entre conocidos. Al año siguiente, Hochschild le compró Ruinas artificiales (2008), una pieza que hizo mientras estudiaba, compuesta por fragmentos de yeso pintados ${ }^{14}$. Si en esa época Miguel escuchaba que Hochschild compraba obras de todos sus amigos, losu empezó su carrera inmerso en esa nueva atmósfera, extraña para quien venía de un momento en que los coleccionistas tenían un perfil bajo. Pero la principal diferencia con Miguel radica en que, antes de lo que losu considera el inicio de su carrera profesional, trabajó desde 2009 en $80 \mathrm{~m} 2$ Livia Benavides, la única galería que lo representa hasta la actualidad ${ }^{15}$. No hay una categoría que describa la función que cumplió, pues era "la persona que está en la galería". Su relación con el mercado no fue un proceso de aproximación progresiva sino de inmersión directa, no tanto porque ingresara a él como trabajador, sino porque el mercado mismo se había expandido hasta hacerse casi indistinguible del campo del arte en general.
Como sugiere Fleck, la "idea iluminista del museo de arte como lugar que se encuentra más allá de las consideraciones comerciales" difícilmente puede sostenerse en la actualidad, cuando los museos adoptan estrategias de branding para competir en el mercado de experiencias de consumo (2014, p. 48). Desde mediados de la década de 2000, museos como el MALI han transitado esa ruta, pero lo crucial para captar el desdibujamiento de los límites entre el campo y el mercado del arte en Lima se encuentra en el solapamiento entre museo y mercado que Borea (2016) ha estudiado en los últimos años a través del seguimiento de los actores que transitan fluidamente ambos espacios institucionales y los intereses de clase que animan su superposición. Este proceso enmarca bien lo que desarrollaré a continuación. Para ello, tomaré como pauta una curiosa declaración de una entrevistada que trabaja en una galería local: "losu lo tiene todo: gana concursos, vende bien y participa en proyectos que no son parte del mercado"16. Hay que tomarse en serio la frase, pero describir datos y experiencias que la confirmen o refuten sería poco interesante. No se trata de desmerecer las tres propiedades que la trabajadora le reconoce al artista, sino preguntarnos por las condiciones en las que esas atribuciones se han asentado. 
Gana concursos (el significado del premio)

Figura 10. losu Aramburu, Ser de su Tiempo I, óleo sobre tela y lámpara de neón, 110 x $200 \mathrm{~cm}$, 2012 (archivo del artista).

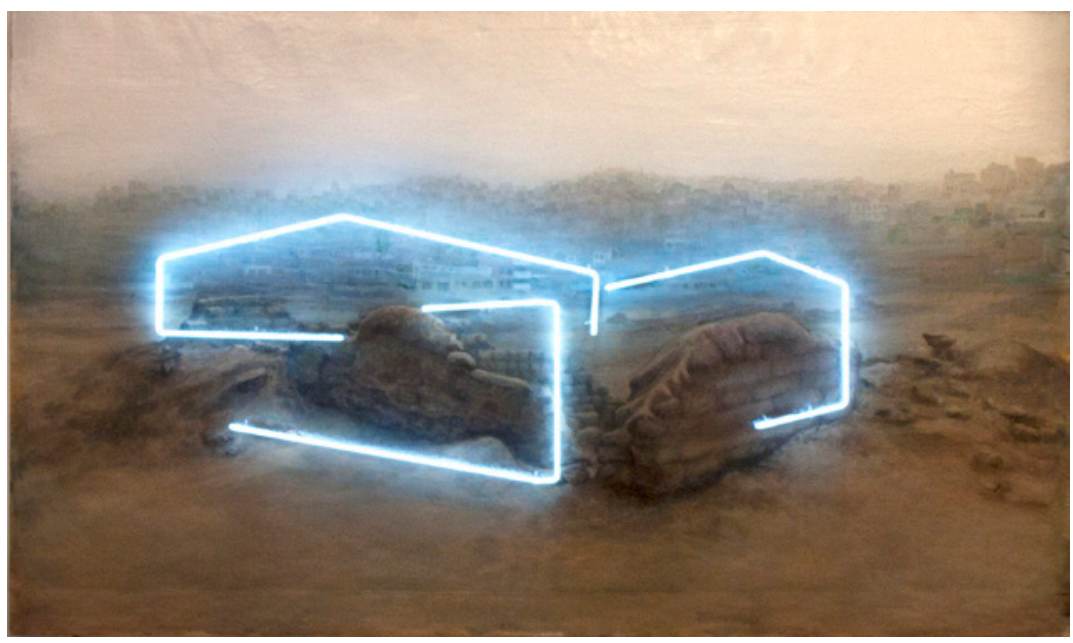

losu piensa que su carrera empezó realmente después de obtener el premio de la III edición del Concurso Arcos Dorados de Pintura Latinoamericana (auspiciado por una franquicia de McDonald's) durante la feria arteBA (Buenos Aires) en 2012, a la que accedió por selección del curador mexicano Pablo León de la Barra. El Premio Adquisición ascendió a 15.000 dólares y ganó con un óleo sobre tela con un neón incrustado, de la serie llamada Ser de su tiempo (2012-2013) (Fig. 10). En ella vemos una huaca abandonada en medio de una ciudad densa y precariamente poblada. El neón completa la desaparecida arquitectura precolombina mediante una forma diagramática que parece un almacén industrial o una fábrica. En la imagen se encuentran la vivienda, el ritual y el trabajo. losu ya reconocía que su obra se iría orientando hacia la exploración de temas y pasajes de la historia peruana -en particular de la arquitectura moderna-, aunque los neones resultaron pasajeros.
Tenía 26 años al recibir el premio y aún no había presentado una exhibición individual, aunque algunos curadores empezaban a llamarlo para muestras colectivas. Además, venía trabajando en $80 \mathrm{~m} 2$ y ya se habían vendido piezas suyas en algunas ferias. El formato de galería que representa a artistas tomaba cuerpo durante esos años en Lima sin consolidarse del todo, así que cuando losu decidió ser artista podríamos decir que ya tenía una galería. Livia le ofrecía desarrollar (¿invertir en?) su carrera, guardar en el almacén la totalidad de su voluminosa producción -un problema para muchos artistas-y, finalmente, compartir las ventas en partes iguales ${ }^{17}$. El haber trabajado en la galería le permitió entender su lógica operativa y, sobre todo, la centralidad de una galería para desarrollar hoy una carrera artística, algo que no parecía tan necesario una década atrás ${ }^{18}$. Aunque no ocurrió así, es ilustrativo imaginar que, después del premio, losu renunció a su trabajo como asalariado para convertirse en lo que le da trabajo a la galería. 
Si para los artistas jóvenes de los años noventa había en Lima un número reducido de galerías (entre las que destacaban Wu Galería, Fórum, Praxis y Lucía de la Puente, con distintas proporciones de representación de artistas contemporáneos), losu y los artistas de mi generación encontraron un circuito de galerías a las que se habían sumado $80 \mathrm{~m} 2$, Vértice, Revólver y algunas más. Desde 2005 operaba el Comité de Adquisiciones de Arte Contemporáneo (CAAC) del MALI y en 2010 reabrió sus puertas el museo al finalizar su remodelación. A inicios de 2013 se inauguró el Museo de Arte Contemporáneo (MAC) y, finalmente, se sabía que las subastas del MALI -que funcionaban desde 1996- ofrecían lotes de arte contemporáneo. Las dos ferias de arte inauguraron en abril de 2013 y para ese momento era claro que la imagen pública de los artistas (prensa, revistas, redes sociales, etc.) era algo que había que producir tanto como la obra.

Todo ello iba tejiendo una visión de algo que no es un conjunto de lugares donde funciona el mercado del arte, sino un verdadero "sistema" de arte contemporáneo donde el mercado cumple un papel estructurante y determinante de lo que los artistas y sus obras son ahora. Siguiendo a Ana Letícia Fialho (2019), un sistema de arte contemporáneo está compuesto por la interrelación entre producción artística, reflexión crítica, instituciones no comerciales e instituciones de mercado. Al igual que en la dinámica reciente del caso brasilero presentado por la autora, el sistema limeño tuvo al mercado como propulsor de su configuración -a diferencia de otros sistemas más "equilibrados"- y la ampliación de sus instituciones llevó a que, bajo el mismo movimiento, apareciera como algo cada vez más abstracto y ubicuo.
Hacia 2010, la mayor parte de los premios de pintura que funcionaron entre los años ochenta y noventa habían desaparecido. Sería lógico pensar que un premio en una feria en el extranjero concentraría todo el valor que antes se repartía entre los múltiples galardones existentes -me refiero al valor lingüístico, en clave saussureana-. Sin embargo, el mayor efecto que generó el premio recibido por losu en 2012 ya fue descrito antes: ratificar que quería ser artista, un impacto principalmente personal. No hubo entrevistas ni textos escritos por sus pares otorgándole el papel de representar la condición existencial de su generación. Después de que, al año siguiente, recibiera el tercer puesto en el concurso Pasaporte para un Artista, las ventas de sus obras incrementaron. Sin embargo, el efecto social de los premios estaba circunscrito al mercado, mas no a una esfera pública que lo excediese. Por un lado, entonces, la diferencia entre los premios recibidos por Miguel y losu consiste en que, al ampliarse el mercado del arte, este se había logrado diferenciar de los viejos espacios de reconocimiento del campo del arte.

Por otro lado, la escena había cambiado sustancialmente: el mercado no era visto como algunos lugares y un grupo de actores (un espacio diferenciado y autónomo de otras esferas sociales), sino como una condición del arte contemporáneo en Lima. Dicha condición pauta hoy las actividades que los artistas deben realizar si desean desarrollar una carrera profesional: formular proyectos y aplicar a residencias en el extranjero para investigar, participar en organizaciones culturales no orientadas al mercado, organizar studio visits con curadores para generar redes, hablar resueltamente del concepto de la obra y del proyecto más grande del que forma parte, participar en las ferias de 
arte tanto locales como extranjeras, etc. Salvo por las ferias -a las que se ingresa mediante una galería-, los artistas son hoy responsables de cumplir con esas actividades. Poco a poco, Miguel empezó a preocuparse por algunas de estas exigencias, mientras losu empezó su carrera cuando ese nuevo ambiente terminaba de reemplazar al que el período previo al boom había configurado ${ }^{19}$. Esa es hoy la atmósfera del arte contemporáneo local.

Vende bien (rangos de precios y tipos de personas)

Tomar los 15.000 dólares recibidos por el premio como el valor de ese cuadro de losu sería el mismo error al que nos vemos inducidos todos los días cuando intercambiamos mercancías por dinero ${ }^{20}$. El valor, en realidad, es la sustancia social -nuestra acción creativa- que se realiza mediante un medio material ante la sociedad (Turner, 2008; Graeber, 2018). El premio no es igual al dinero porque lo que está en juego en el primero es la importancia social de la acción a premiarse, que puede o no asumir la forma dineraria. El que muchas veces las personas critiquen al ganador de un concurso o impugnen al jurado bastan para entender que este es una vía para realizar socialmente el valor. El premio recibido por losu, entonces, representa el valor de su trabajo, pero el monto que le transfiere no debe ser visto como el precio alcanzado por su obra en el mercado, sino como una representación imperfecta bajo el capitalismo -aunque económicamente generosa- del valor que el jurado reconoció en ella. De lo contrario, el precio aparecería inflado en el mercado, cosa nada conveniente para un artista joven que, por más que hubiese vendido algunas obras, no pasaba aún por el ritual de la primera muestra individual.

losu lleva un registro casi exacto de todas las operaciones que ha realizado en el mercado desde 2008, cuando aún estudiaba en la universidad. Me compartió ese documento, pero sin los nombres de los compradores, para conservar su mercado bajo un ambiente de confianza recíproca. Sin embargo, lo que aquí interesa es el proceso de establecimiento de los precios, sobre todo el asegurarse que no se alejen demasiado de lo que el artista considera apropiado. losu acuerda los precios con Livia y anota en su registro un "precio de lista", junto a la fecha en la que se estableció el monto. No incluyen impuestos, pero toman en cuenta el reparto al $50 \%$ entre ambos. Además, es normal que el precio de lista sea mayor al precio de venta final, pues se debe incluir el descuento propio de la negociación ${ }^{21}$. Sin embargo, estos acuerdos no siempre se cumplen o los montos establecidos no están a la mano y la galerista los adjudica "al ojo". "El tema es que en la galería no siempre hay una lógica muy clara de los precios que ponen -dice losu- y yo al principio me frustraba un montón con eso y trataba como de armar fórmulas más precisas del precio según, no sé, el tipo de obra o el tamaño. Pero al final me di cuenta que no importa"22.

Mientras le importaba, sin embargo, veía como algo desfavorable que Livia le pusiera el precio al ojo a sus obras, sin atender a las similitudes y diferencias que estas guardan entre sí. Por una parte, era un problema en la medida en que hubo momentos en que ciertas personas compraron regularmente su obra, pero, como eso no cristalizó en alguien que "lo coleccione", perdió relevancia la fluctuación arbitraria de sus precios. Aunque su 
principal mercado es el limeño, "es reconocido, pero no tiene coleccionistas", como dijo una trabajadora de galería ${ }^{23}$. Por otra parte, como él mismo pudo constatarlo cuando trabajaba para la galería, en las ferias hay algunas personas estudiosas que están atentas a los precios y discursos con los que estos se justifican durante la venta. Entre ambos factores se ubica el abandono de una fórmula para determinar el precio de sus obras, pero eso no significa que puedan costar cualquier monto. Lo que importa es mantenerse dentro de un rango de precios que corresponda con la obra ofertada: hasta 2.000 dólares, por un lado, y de 2.000 a 10.000 , por otro. Para losu, entonces, "da lo mismo" el precio con tal de que se mantenga dentro de los rangos acordados, y a su vez esto le permite a su galerista tener un poco más de espacio para negociar durante la venta ${ }^{24}$.

"Si una pieza cuesta más de 2.000 dólares, es necesario el rollo [discurso]", dice una trabajadora de galería. ¿Qué decir cuando alguien se interesa en la compra de una obra? Para saberlo es necesario hablar con los artistas, pero sobre todo ser capaz de articular un discurso coherente por sí mismo. Así, los rangos de precios sugeridos por losu deben corresponder con dos cosas distintas: por un lado, con la obra en cuestión, ya que debe parecer razonable el monto en relación con lo que un potencial comprador podría ver en ella; por otro lado, el monto debe ser adecuado para "el tipo de persona que quiere comprar", al decir de losu. Algunas personas requieren de un discurso que muestre una dimensión conceptual no siempre visible en las obras, o desean escuchar quién es el artista y qué ha conseguido en su vida (muestras importantes, coleccionistas famosos que lo hayan comprado, buenas críticas de personas influyentes, etc.), mientras otras que parecen ser las menos en el segmento contemporáneo del mercado- responden a una conexión directa y sensible con lo que miran. Hay que saber discriminar cuándo se trata de tal o cual tipo de persona, y tal vez lo principal sea percibir o sentir ante quién está uno, lo que vuelve a indicar que la mística del connaisseur aquí aplica para el discernimiento de las personas mismas que aparecen en el mercado.

Trabajadoras, galeristas o artistas: a quien sea que le toque ocuparse del proceso de venta se le exige tener las capacidades antes señaladas. También debe tener en mente algo así como el "beneficio simbólico" que una venta puede generar, como lograr una venta para una "súper colección" -usualmente propiedad de personas "súper ricas" que podrían pagar más que el precio de lista- y saber rebajar lo suficiente para no desanimarlos. Así, de concretar la venta, el "valor simbólico" del artista incrementará y subirán sus precios. 
Figura 11. Iosu Aramburu, Plan piloto de Lima, varios materiales cubiertos con cemento, mesa de metal y madera, 226 × 248 × 366 cm, 2015. Vista de sala en exposición Revisiones (MALI), curada por Sharon Lerner entre febrero y agosto de 2017 (fotografía: Juan Pablo Murrugarra, archivo del artista).

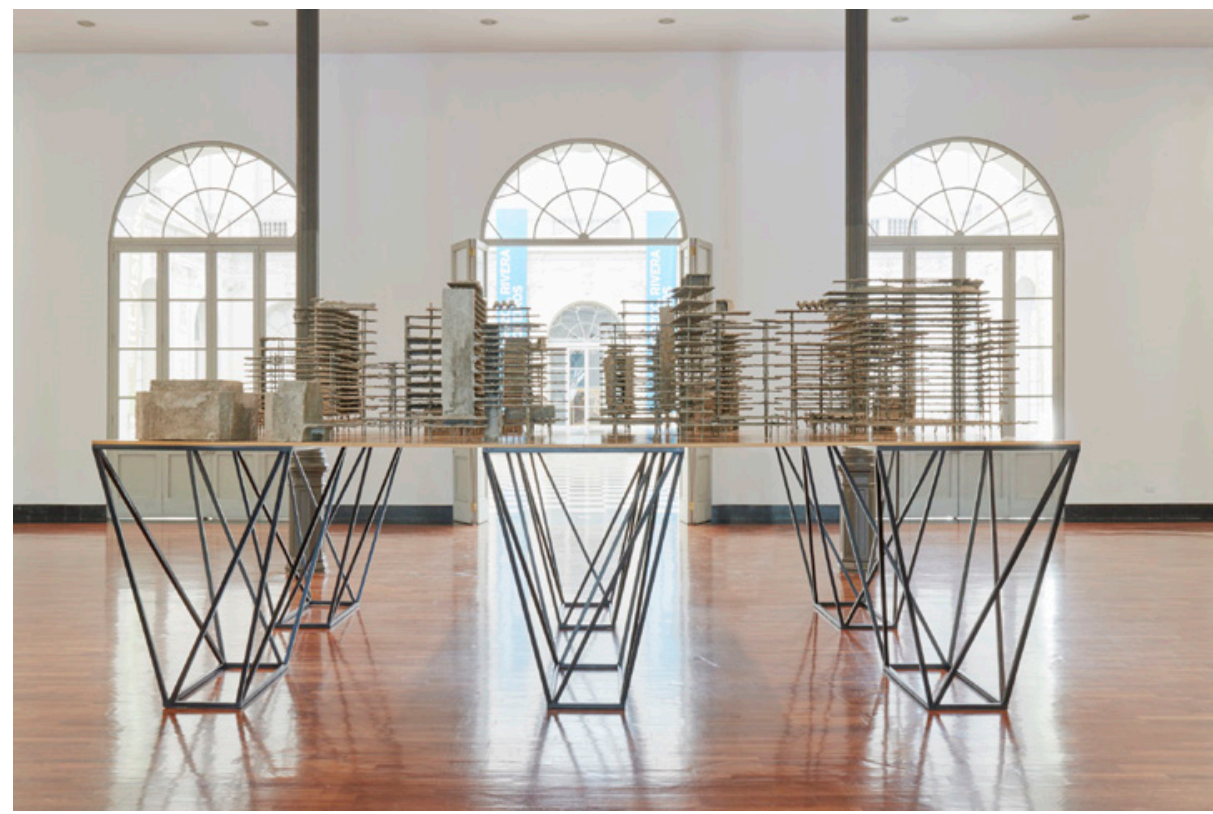

Un ejemplo es la venta del Plan piloto de Lima (2015), una enorme pieza adquirida por el Comité de Adquisiciones de Arte Contemporáneo (CAAC) del MALI muy por debajo del precio de lista ${ }^{25}$ (Fig. 11). En el texto que escribió para su muestra Modernidad histérica, losu plantea recuperar las utopías urbanas del modernismo peruano ante el caos limeño. Pero esa recuperación es consciente de la posibilidad distópica que acecha siempre a toda forma utópica. losu parte de una premisa dialéctica para interpretar la maqueta como algo que tiene valor en potencia: de haber sido realizada como una ciudad racional, la maqueta sería hoy una prefiguración de una vida más plena; vista desde el presente, la maqueta aparece como una imagen idealizada de un futuro que nunca llegó. Por ello la pieza de losu incluye en su propia forma la corrosión y "el polvo que se acumula en el concreto” (Aramburu, 2015).

El resultado es ambivalente a sabiendas. Para García Canclini (2012 [2010]), el arte "es un modo de hacer que deja algo irresuelto" (p. 62), y en esa ambivalencia -no dada sino conseguida en algunas obras, según el autorreside la figura del artista como "trabajador del disenso", que ya no cree "en la concepción binaria que en otro tiempo oponía el arte hegemónico al alternativo, porque los movimientos y las instituciones que representarían esas opciones no son universos compactos y coherentes" (pp. 139-140). Hay tránsitos entre uno y otro, y el mercado en algunas ocasiones funge de mediador. El discurso -el análisis de las formas utópicas de nuestra historia-, la 
investigación, los costos y demás factores que intervinieron en la producción de esta obra; en suma, el cúmulo de acciones que esta esconde bajo su forma objetiva, son suficientes para que rebajar el precio no importe ante la posibilidad de preservar la objetivación del valor (la obra) en las condiciones privilegiadas que ofrece el museo. Este aparece en el mercado como un "tipo de persona" al que le importa mucho el aspecto discursivo de la obra. He ahí lo que está en juego en la transacción económica donde, en apariencia, el precio simbolizaría una pérdida de valor. Este tipo de ventas son más bien escasas en el mercado local. Usualmente no hay una coordinación tan precisa entre los aspectos discursivos o estéticos y los precios -menos aún una consideración sobre el valor, aunque implícita, como en el caso anterior-.

Figura 12. Obras de losu colgadas en el showroom, galería $80 \mathrm{~m}^{2}$ Livia Benavides, julio 2018 (fotografía del autor).

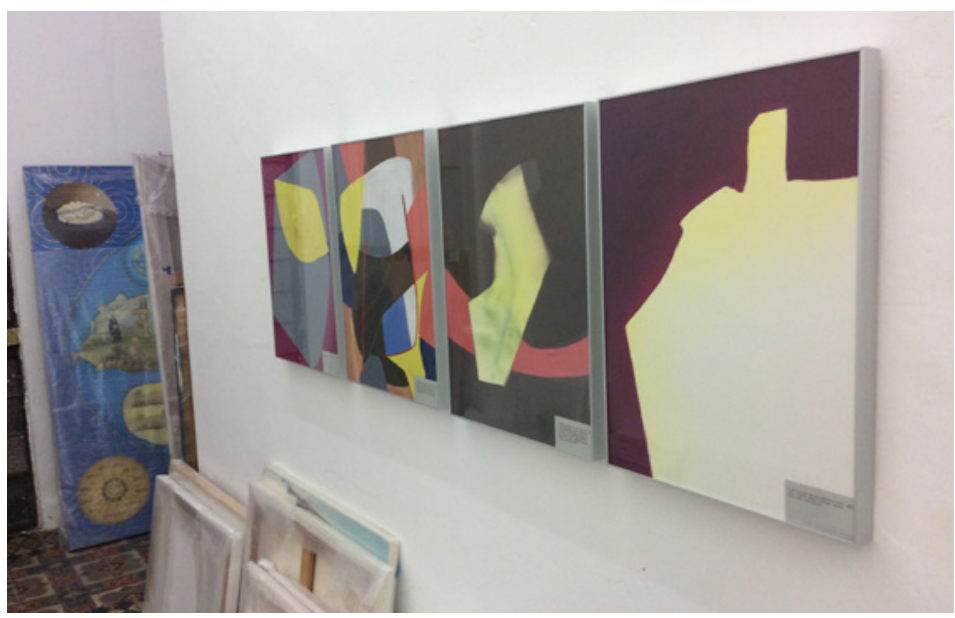

Figura 13. Obras de losu colgadas en el showroom, galería 80 $\mathrm{m}^{2}$ Livia Benavides, octubre 2018 (fotografía del autor).

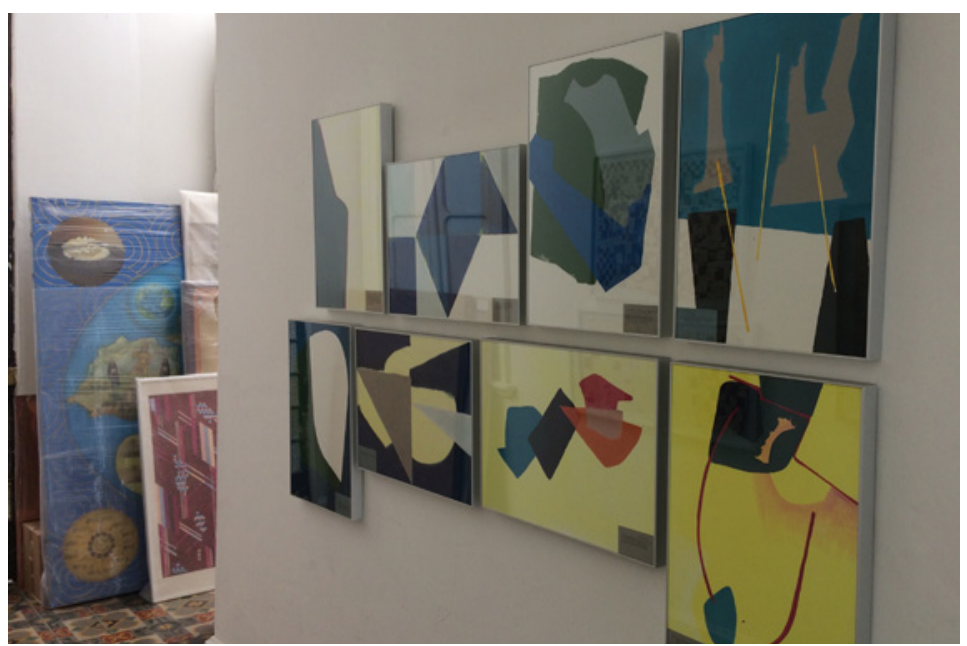


Al fondo de la casona barranquina donde funciona $80 \mathrm{~m} 2$ Livia Benavides hay un showroom en el que un conjunto de obras rota periódicamente. Al terminar el pasillo que divide las dos alas de espacios de exhibición entramos a un espacio amplio en el que, a la izquierda, cuelgan pinturas sobre papel de formato mediano de la Charte d'Athènes (2014-2018) de losu (Figs. 12 y 13). Esa noche la galería sería una de las sedes de un seminario sobre arte contemporáneo que el MALI organizó, destinado a recaudar fondos. El precio por las ocho sesiones (350 dólares) planteaba una brecha de acceso, pero el curso no pretendía ser un espacio de difusión. A Max Hernández-Calvo le tocaba dar la charla sobre el mercado local esa noche. Las características del taller y el tema a tratar reclamaban especial cuidado en la organización del espacio. Entre las dos fotografías que tomé de las Cartas de Atenas había tenido lugar este evento.
En cuanto a las obras de losu, el único cambio fue añadir una segunda fila de la misma serie. A menudo se escucha que "las Cartas se venden bien". Aún más: "son de venta fácil" ya que jalan el ojo sin requerir que el comprador escuche un "rollo" sobre qué significan -de lo que no me ocuparé aquí-. La venta en bloque -se venden de a cuatro por 3.500 dólares- tiene sentido cuando se trata de una serie demasiado extensa (95) que, de venderse por unidades (875 dólares), malgastaría el tiempo de Livia y sus trabajadores. En ese sentido, la obra reclama pensar una estrategia de venta específica para no echar a perder el valor del trabajo. Ya en el showroom, sin embargo, las Cartas deben ser vistas en relación con las otras piezas de losu en el mismo espacio, como los tres cuadros de la serie Una nueva era (2018) (Fig.14). Cada uno se ofrece en 7.000 dólares más impuestos y un descuento generoso es viable si se compran más de dos, como ocurrió hace un tiempo.

Figura 14. Showroom de galería 80 $\mathrm{m}^{2}$ Livia Benavides, octubre 2018 (fotografía del autor).

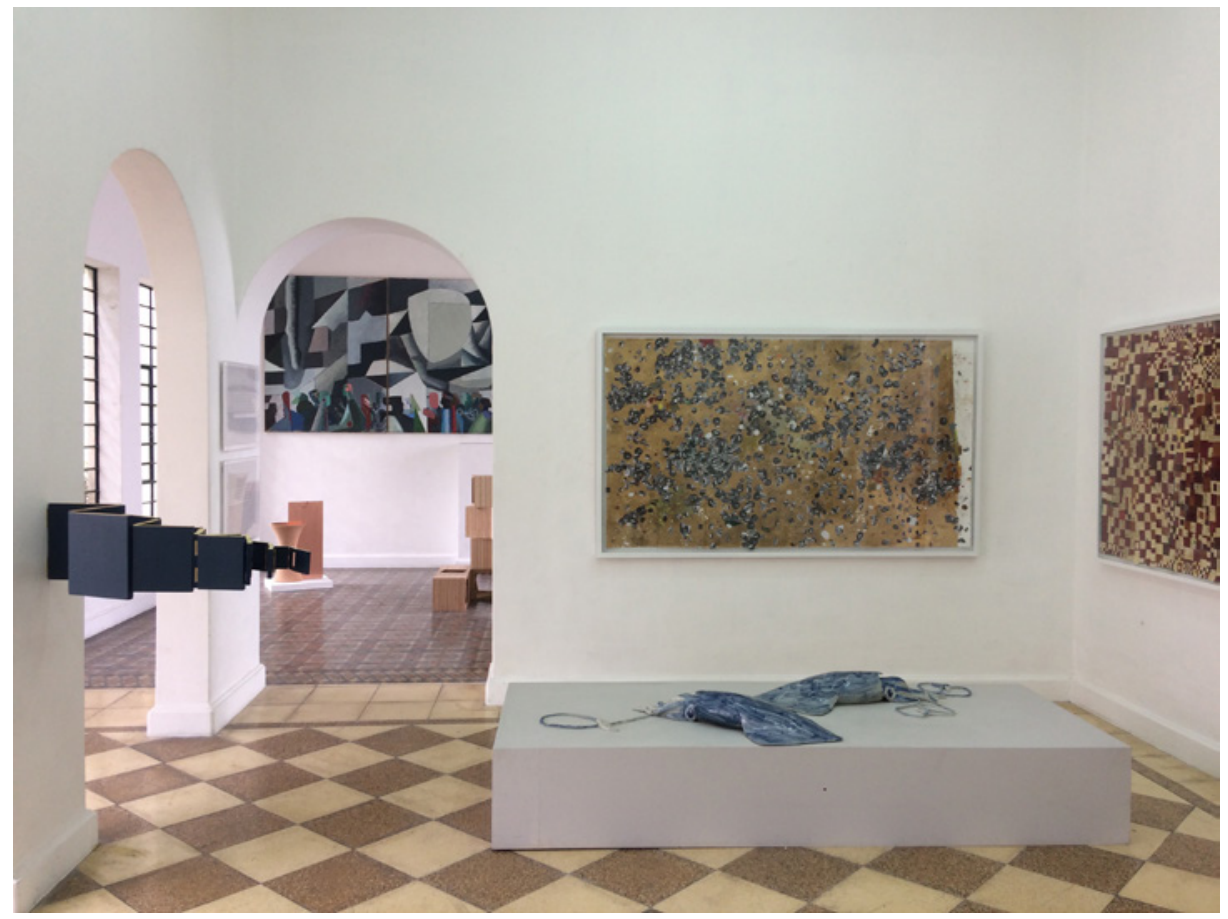


Entre ambas obras se configura el lugar de losu al interior del conjunto de artistas representados por la galería: con las Cartas obtienes cuatro pinturas por un precio similar al de un dibujo de Rita Ponce de León o una pequeña escultura de Ximena Garrido-Lecca; al comprar un cuadro de Una nueva era obtienes una pintura algo más pequeña que las más recientes de Sandra Gamarra, que pueden costar casi cuatro veces más. La obra de losu se ubica en un rango de

Participa en proyectos que no son parte del mercado (la otra burbuja) precios medios que, según el tipo de persona, ofrece una salida fácil a una compra decorativa -uno de sus principales usos- o a alguien que se ponga a calcular precios relativos para invertir bien su dinero. Frente a obras de artistas peruanas cuya carrera se desarrolló principalmente en el extranjero, losu parece no estar demasiado ansioso por elevar las cifras que ha conseguido a lo largo de una carrera hecha desde una galería limeña.

Figura 15. Vista de la exposición Una nueva era, Museo de Arte de San Marcos, junio-julio 2018 (fotografía: Juan Pablo Murrugarra; archivo del artista).

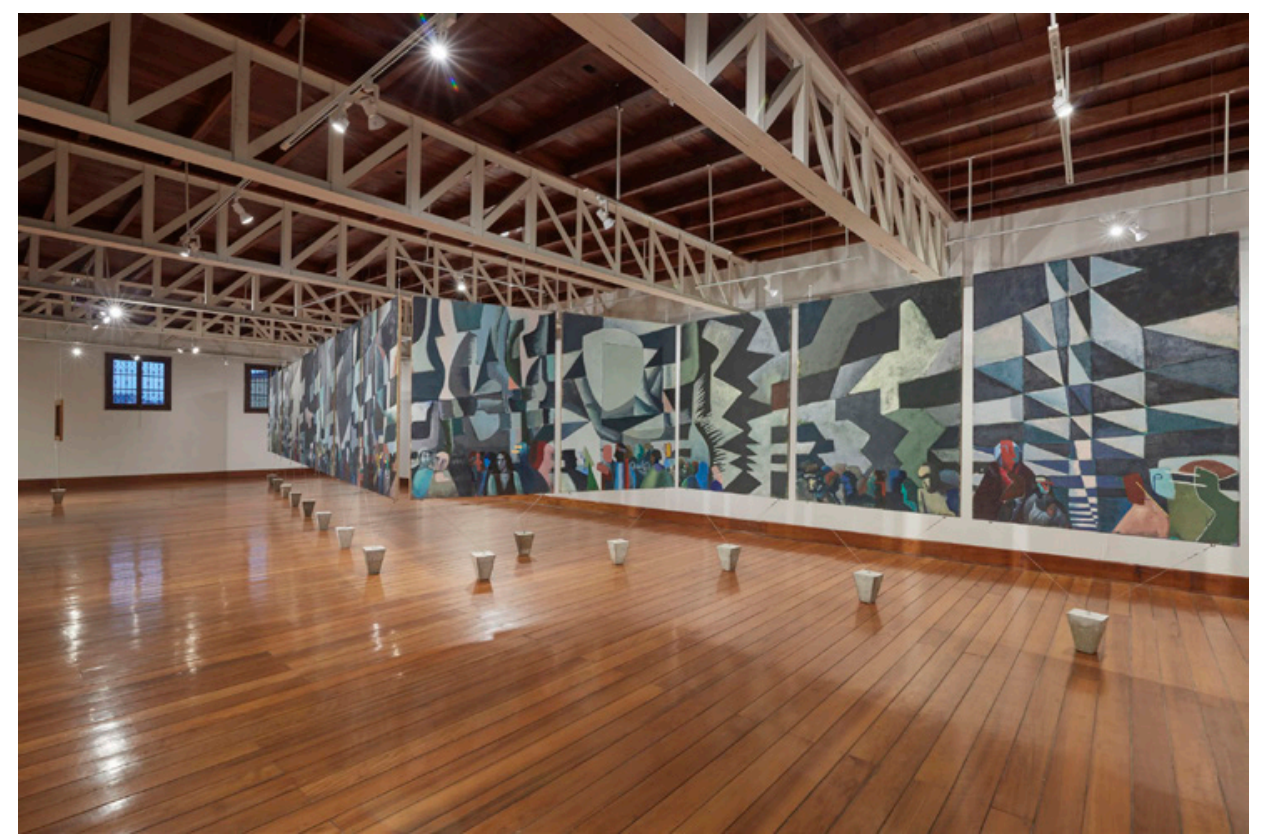

Vistas desde el techo, las 14 pinturas que componen Una nueva era (Fig. 15) forman algo parecido al diagrama de un rayo. Frontalmente aparecen como un mural que se conecta por las líneas diagonales que componen el espacio figurativo de cada cuadro. También puede recorrerse la instalación por detrás y encontrar una pequeña pintura en la que vemos un loro rojo. La idea es que se hagan visibles tanto la representación como el soporte físico de las obras e incluir esta mirada en la lectura de la instalación. En el primer plano del mural 
vemos una serie de personajes construidos a partir de formas, trazos y estrategias de composición tomadas de las vanguardias del siglo $\mathrm{XX}$-excluyendo los realismos socialistas- que confrontan un conjunto de formas abstractas. Al recorrerlas, esas formas parecen edificios, monumentos o patrones que remiten a diseños geométricos o celosías modernistas.

Un año después de que Miguel, losu y otros artistas volaran a Madrid para la inauguración de la primera exposición de la colección Hochschild, los que fuimos convocados para seleccionar las propuestas enviadas a una convocatoria del Museo de Arte de San Marcos en 2018 discutíamos cuáles serían los ganadores. Fue fácil la inclusión de la propuesta de losu entre los premiados, aquellos que obtendrían una exhibición temporal para cada uno en el museo universitario. Durante la sesión no apareció ni la sombra del mercado, por lo que algo de razón tiene la entrevistada que le atribuyó a losu las tres cosas que organizan este apartado: gana concursos (como este), vende bien (lo que no importó durante la decisión) y participa en proyectos que no son parte del mercado.

En apariencia, este premio no forma parte del mercado por varios motivos: primero, porque proviene de una institución cultural administrada por el Estado que no tiene fines comerciales; segundo, porque los premios otorgados fueron debatidos con independencia a la inserción y/o desempeño de los postulantes en el mercado -entre los cuales hubo varios jóvenes recién egresados de sus estudios-; tercero, porque el premio no se acerca a los términos en los que se mueve el mercado, pues no transfiere dinero. Así, este premio sería una muestra de que es posible pensar el valor del arte por fuera del mercado.
Este razonamiento es estático. Busca la manera de eludir el mercado para encontrar un punto de inalienabilidad en medio de una situación que es percibida como totalmente alienada y alienante. Desde las perspectivas parciales mediante las cuales las instituciones del campo del arte se evalúan recíprocamente, este premio y sus formas de realizar el valor de los proyectos ganadores parecen no tener nada que ver con el comercio. Por el contrario, una mirada procesual a todo nivel del campo del arte permite comprender que el verdadero problema no es si forma parte o no del mercado, sino cómo, al interior de dicho campo, opera el mercado directa o indirectamente. En el mejor de los casos, diría alguien desde una perspectiva que asume cierto enfoque procesual, pero persiste en condenar el mercado, este premio aporta un guion más al curriculum vitae del artista que justificaría un alza de precios. En el peor de los casos -que no es este, hasta donde mi participación me permite entenderlo-, podría revelarse que el jurado o la organización había acordado destinar los premios en función de intereses comerciales, como seguramente ha ocurrido en otros concursos.

Sea como fuere, la mañana que pasé evaluando los proyectos para el Museo de Arte de San Marcos (MASM) fue parecida a la noche del conversatorio en el ángulo de la instalación de losu: las dos son burbujas que aíslan el arte del mercado y nublan sus vínculos recíprocos. Desde aquí, podríamos continuar describiendo otras experiencias recientes en las que losu participó que no forman parte del mercado directamente. Esos varios frentes son clave hoy si lo que busca un artista no es solamente el éxito comercial. De abandonar esos espacios o proyectos en los que el mercado no predomina, lo más seguro es que se empezaría a 
cuestionar su valor, precisamente aquello que buscan realizar socialmente artistas como losu y Miguel.

\section{Conclusiones: figuras del artista profesional}

Los premios son formas de reconocer el valor de una acción, pero no pueden ser vistos como si realizaran el valor en el vacío. Hoy el mercado del arte se ocupa de integrar formas de valor distintas: cuando hay dinero de por medio, el premio marca un estándar que los artistas a veces toman como guía para establecer precios, sobre todo si se trata de un premio adquisición (esto lleva a que los precios se inflen); cuando hay exhibiciones, publicaciones, eventos públicos u otras formas de premiar, el mercado toma nota y suma esas formas a una lista de distinciones que puede emplear como garantes del valor de los artistas. Al decir de los artistas no estoy confundiendo los términos por una inversión fetichista: lo antes expuesto muestra procesos de subjetivación mediante los cuales los artistas personifican el arte, esa forma de la inalienabilidad que tanto los espacios comerciales como los que se desenvuelven al margen del mercado comparten como la fuente del valor que buscan realizar.

Desde fines de la década de 1990 hasta la actualidad, el mercado del arte contemporáneo en Lima ha ido adquiriendo esa centralidad que hoy le da suficiente fuerza para aparecer como única vía para realizar el valor de la acción creativa de los artistas. Esto no es necesariamente así, aunque es verdad que parece ser la principal vía para obtener las dos cosas que los artistas, en cuanto trabajadores independientes de la producción de mercancías (Durán, 2015) requieren para continuar con su desarrollo: reconocimiento social y dinero regular, que no son sino dos "refracciones de lo mismo" (del valor), diría Graeber (2018). losu y Miguel compitieron por el primer Premio Arte Contemporáneo ICPNA 2018. Fueron 10.000 dólares y una exposición para el año 2019 que el jurado otorgó a losu. Algunas personas de la escena cuestionan la decisión en conversaciones informales y posts de Facebook por la cercanía de algunos miembros del jurado con el ganador. Se esperaba una abstención o una explicación sobre cuánto de la subjetividad del jurado intervino. La crítica aquí no dice mucho sobre el valor del trabajo de losu, sino sobre su forma de realización. A pesar de que "no tiene coleccionistas", losu es reconocido: nadie cuestionó públicamente el valor de su trabajo. Y, cuando del valor se trata, la dimensión pública de su realización es central.

Al comparar las condiciones en las que Miguel y losu recibieron sus premios más importantes, resaltan diferencias en cuanto al reconocimiento público que generaron. Cuando Miguel recibió el premio Telefónica transitaba la vía mediante la cual el campo del arte en Lima "colocaba" artistas en el extranjero. Eventualmente, estos podrían consagrarse y enviar remesas, económica y simbólicamente hablando, cuya finalidad sería articular la escena al circuito global del arte. El premio que losu recibió en arteBA, por su parte, no tuvo mayores resonancias locales y sus recientes concursos ganados dan cuenta de una audiencia social fragmentada, que no reclama para sí la importancia de sus logros. Para ambos, sin embargo, los premios indicaron que su carrera como artistas era viable, pero las audiencias ante las que aparecieron han cambiado. 
Acaso esta diferencia responda a la propuesta de Claudio Iglesias (2014) cuando sostiene que los años dos mil fueron "la década inexistente" en el arte latinoamericano. Esa inexistencia subraya el efecto que genera la predominancia del mercado del arte en la configuración de los sistemas de varias ciudades de la región, a saber, una pluralización estética caracterizada por un "vacío semántico" (p. 24). A mi juicio, una mejor forma de caracterizar dicho efecto sería subrayar la incapacidad del sistema configurado por el mercado para incidir en una arena de reconocimiento social más amplia, como aquella aún operativa en Lima a inicios de esa década. Desde luego, este efecto merece ser examinado según las particularidades de cada sistema en la región, y el análisis de Iglesias avanza en la discusión sobre las diferentes formas de profesionalización que encontramos en ciudades como Santiago -donde el sistema parece articularse alrededor del financiamiento estatal- o Buenos Aires -donde el sistema guarda estrechas relaciones con las "industrias creativas"-. El caso limeño aquí presentado se ubica en un punto intermedio que valdrá la pena analizar más extensamente en otras investigaciones.

Ahora bien, ¿qué podemos concluir a partir de la comparación de las trayectorias profesionales antes descritas? Sin atender a las diferencias de edad y extensión de sus carreras profesionales, y a riesgo de ser malinterpretado, podríamos decir que la obra de Miguel "vale más" que la de losu, en la medida en que su obra temprana logró inscribirse en el imaginario histórico de "grandes pintores peruanos" como un momento culminante ante el umbral de una contemporaneidad artística que el entusiasmo ambiente desligaba de lo que, junto a las nuevas formas globalizadas del arte, anunciaba: la expansión del mercado. En ese sentido, dicho valor fue realizado antes del boom y para Miguel sería fácil vivir de la reedición y/o cita infinita de los icónicos cuadros con los que se convirtió en un "dios" local. De alguna manera, su carrera empezó con el "juicio de la historia" que lo ubicó dentro del canon ${ }^{26}$. Tempranamente, sin embargo, desarrolló su obra en otras direcciones que avanzaron en paralelo a la expansión del mercado local, sin dejar de tener un buen desempeño comercial (aunque hubo épocas difíciles), pero marcando cada vez más su diferencia respecto del reconocimiento social "más allá" (en verdad antes de la expansión) del mercado que recibió tempranamente en su carrera. losu, por su parte, empezó en un contexto de mayor competencia y con las exigencias propias del sistema del arte contemporáneo (residencias, fondos, redes, etc.).

Además de erosionar las bases de la solidaridad entre pares, el boom desestructuró las instancias de crítica, prensa, promoción y exhibición pública que funcionaron hasta 2002, cuando la Bienal tuvo su última edición. Sin embargo, la nueva atmósfera del mercado le ha permitido a losu conocer mejor su funcionamiento interno y usarlo como un medio para sostener su producción y generar un público propio. Es de los pocos artistas en Lima que se preocupan por editar un catálogo para cada exhibición individual, por ejemplo. Aunque hoy parece imposible gozar del reconocimiento público de hace apenas dos décadas -pues el mercado habría erosionado las instituciones no comerciales que lo soportaban-, lo cierto es que el valor de la obra de losu se realiza mediante la venta sostenida de su trabajo. Y en la sociedad capitalista, como diría el joven Marx (1968), el dinero da poder a quien lo lleva en los bolsillos. 
Un último punto para la comparación entre ambas trayectorias tiene que ver con las posiciones frente al mercado que Miguel y losu adoptan actualmente. Como vimos, para Miguel es posible que el sentido de sus obras se desvirtúe cuando sus nuevos propietarios les dan un uso ajeno al que considera adecuado -como vimos con los Tipos, Miguel rechaza su conversión en "postales"-. Por su parte, losu parece haber aprendido que así funciona el mercado del arte, pues solo en ocasiones particulares la intención, el discurso e inclusive la posición ideológica del artista se conservan al pasar por el mercado $-y$, en general, por el campo del arte-. Que algunas de sus obras se vendan para fines decorativos poco importa. El circuito de galerías en el que Miguel participó hasta hace muy poco ubicaba -y aún lo hace- a las decoradoras de interiores como las responsables de que, después de la venta que igual siempre hay que concretar, las obras se desvirtúen por usos inadecuados.

Es razonable que, para los artistas, el desarrollo de su obra y su participación en el mercado sean vistos como dos dimensiones independientes de su práctica. Al asumir la forma de la obra -una forma objetivada que circula socialmente e interactúa con otros

\section{Notas}

\footnotetext{
${ }^{1}$ El concurso de la Telefónica ofrecía un viaje a España y 20.000 dólares como estipendio para una estadía de un año. Para Villacorta y Hernández-Calvo (2002), ambos concursos mantuvieron un carácter conservador al otorgar los premios. Es importante anotar que los concursos de arte en el Perú son de carácter privado -salvo el concurso del Banco Central de Reserva del Perú-. Recientemente, el Ministerio de Cultura ha establecido nuevos incentivos para la promoción de las industrias culturales y las artes, aún sin resultados observables.

${ }^{2}$ A partir de catálogos de subastas del MALI obtuve un conjunto de datos sobre su desarrollo entre 2007 y la actualidad, con base en
}

actores-, esa independencia tambalea y los artistas se ven obligados a reevaluar su posición inicial: pese a su trayectoria, a Miguel le preocupa el destino de sus obras en la dimensión privada del consumo, donde el valor se realiza no ya bajo la forma del dinero, sino como uso. Más allá de lo que el artista considere correcto o incorrecto, es ahí donde su obra lo comprometerá práctica y materialmente con otros, no siempre alineados con lo que piensa o desea. De ahí que las pinturas por encargo no formen parte de su obra, y no lo comprometan ni con lo que representan ni con los fines a los que son destinadas en la esfera privada. Por su trayectoria, losu ve el mercado como un aparato para "transportar objetos al futuro" que permite garantizar la permanencia de su obra y, mediante ella, de su propia persona ${ }^{27}$. Al circular bajo varias formas y distribuirse en espacios que van desde el museo hasta las paredes de la burguesía, la obra de losu parece estar construyendo la base material necesaria para que, cuando llegue el "juicio de la historia", el valor de su obra se realice de facto ante una audiencia que no necesariamente supo de qué se trataban esas pinturas en primer lugar. Como quien aspira a lograr que, súbitamente, alguien se vea comprometido con algo que ignora.

las anotaciones de asistentes que me proporcionaron sus catálogos, además de otros que conseguí en puestos de venta de libros de segunda mano. Pese a que es usual que no todas las ventas se concreten tras la subasta, el carácter performativo de la puja y compra ante el auditorio es de por sí un índice de las atmósferas generales de cada edición de las subastas.

${ }^{3}$ Entrevista a Miguel Aguirre, 30 septiembre 2018.

${ }^{4}$ Pude entrevistar a personas de las cuatro galerías limeñas con las que Miguel ha trabajado entre 1999 y la actualidad, no así de aquellas ubicadas en Europa con las que mantiene representación desde 2006. 
${ }^{5}$ Entrevista a Miguel Aguirre, 11 junio 2018.

${ }^{6}$ Entrevista a Frances Wu, 29 agosto 2018.

${ }^{7}$ La primera época de Wu Galería va de 1998 hasta 2005, y en el primer grupo de artistas jóvenes que representaron estaban Sandra Gamarra y William Córdova -ambos representados actualmente en Lima por 80m2 Livia Benavides-, además de Miguel. En esa época exhibieron muestras individuales de artistas mayores, como Carlos Runcie Tanaka y Fernando de Szyszlo, además de la primera individual de Christian Bendayán. La galería me proporcionó algunos datos sobre su historia que pronto publicarán en un libro.

${ }^{8}$ Aunque sea una dimensión crucial en el análisis de las obras que siguen, no me detendré en la discusión sobre la representación de la cultura popular que ofrecen, sino en los aspectos económicos que me permiten continuar la reconstrucción de la carrera de Miguel. En otro lugar ofrecí una interpretación crítica de una de estas obras (Mitrovic, 2019).

${ }^{9}$ Ver http://hotelb.pe/.

${ }^{10}$ Entrevista a Miguel Aguirre, 8 agosto 2018.

${ }^{11}$ Los Tipos de Lima formaron parte de la exhibición Próxima parada. Artistas peruanos en la colección Hochschild (Sala Alcalá 31, Madrid), curada por Octavio Zaya en febrero de 2017.

${ }^{12}$ Entrevista a Miguel Aguirre, 11 junio 2018.

${ }^{13}$ Entrevista a Lucía de la Puente, 24 septiembre 2018.

${ }^{14} \mathrm{Al}$ igual que los Tipos de Lima de Miguel, esta pieza participó en la exhibición de la colección Hochschild en febrero de 2017 en Madrid.

${ }^{15}$ Empezó a trabajar cuando aún la galería se llamaba $80 \mathrm{~m} 2$ arte\&debates, proyecto que fundó Antoinette Arévalo en 2006. Livia Benavides se volvería su socia alrededor de 2010 y posteriormente pasaría a ser la única propietaria.

${ }^{16}$ Entrevista a trabajadora de galería, julio 2018.

\section{Referencias bibliográficas}

Aguirre, M. (1997). Historia del gris del rojo amor (Folleto). Lima: Sala Luis Miró Quesada Garland.

Aramburu, I. (2015). Modernidad histérica (Catálogo). Lima.

Borea, G. (2016). Fueling museums and art fairs in Peru's capital: The work of the market and multi-scale assemblages. World Art, 6(2), 315-337. doi: 10.1080/21500894.2016.1213310

Cárdenas, M. A. (2001). Miguel Aguirre: vendrá la muerte y tendrá tus ojos. La República, 7 agosto. Recuperado de https://larepublica. pe/archivo/323928-miguel-aguirre-vendra-la-muerte-y-tendra-tus-ojos.

Durán, J. M. (2015). La crítica de la economía política del arte. Murcia: Centro de Documentación y Estudios Avanzados de Arte Contemporáneo.

Fialho, A. L. (2019). Mercado de arte global, sistema desigual. Revista do Centro de Pesquisa e Formação, 9, 8-41.

Fleck, R. (2014). El sistema del arte en el siglo XXI: Museos, artistas, coleccionistas, galerías. Buenos Aires: Mardulce.

García Canclini, N. (2012 [2010]). La sociedad sin relato:
${ }^{17}$ Entrevista a losu Aramburu, 18 junio 2018.

${ }^{18}$ Entrevista a losu Aramburu, 9 octubre 2018.

${ }^{19}$ Aunque parezca un típico argumento estructuralista que presenta la subjetividad como un efecto de procesos impersonales que suceden a sus espaldas, ambos artistas han participado activamente en ellos, imprimiendo un posicionamiento propio ante las exigencias sociales de ser un artista profesional. Al decir de Nathalie Heinich (2017), estamos ante un proceso general de configuración de un nuevo "paradigma" para la producción artística (el arte contemporáneo), aunque una discusión mayor ahondaría en revisar la analogía que la autora presenta entre el arte y el funcionamiento de los paradigmas científicos a través de categorías ideológico-políticas, como la de hegemonía.

${ }^{20}$ Al participar en la edición de arteBA en la que su obra concursaba, losu y su galerista habían establecido el precio del cuadro en cerca de 4.000 dólares por si apareciese alguna oferta en caso de no ganar el concurso.

${ }^{21}$ Entrevistas a losu Aramburu, 18 junio 2018 y 9 octubre 2018.

22 Entrevista a losu Aramburu, 9 octubre 2018.

${ }^{23}$ Entrevista a trabajadora de galería, 25 septiembre 2018.

${ }^{24}$ losu Aramburu, comunicación personal, diciembre 2018.

${ }^{25}$ No me detendré en ello, pero anoto que el MALI también tiene obras de Miguel, aunque ingresaron a la colección por donación del artista.

${ }^{26}$ Como dice Moulin, el juicio de la historia permite que la singularidad o la "rareza" de la obra de arte se constituya como "valor artístico" a partir de la definición de "el lugar del artista en la historia del arte y el lugar de una obra determinada en la producción total del artista" (2012, p. 19).

${ }^{27}$ Entrevista a losu Aramburu, 20 agosto 2018.

Antropología y estética de la inminencia. Buenos Aires: Katz.

Graeber, D. (2018). Hacia una teoría antropológica del valor: La moneda falsa de nuestros sueños. Buenos Aires: Fondo de Cultura Económica.

Graw, I. (2015). ¿Cuánto vale el arte? Buenos Aires: Mardulce.

Heinich, N. (2017). El paradigma del arte contemporáneo: Estructuras de una revolución artística. Madrid: Casimiro Libros.

Hernández-Calvo, M. (2009). Una coyuntura que no fue. Ramona, Revista de Artes Visuales, 89, 26-30.

(2018). Texto sin título. En Premio Arte Contemporáneo ICPNA 2018 (Catálogo de exhibición) (p. 10). Lima: Instituto Cultural Peruano Norteamericano.

Iglesias, C. (2014). Falsa conciencia: Ensayos sobre la industria del arte. Santiago: Metales Pesados.

León-Xjiménez, C. (1997). Compartiendo los amores. El Sol, 24 mayo, p. 7B. Recuperado de http://inca.net.pe/assets/objeto/ compartiendo-los-amores6/. 
Marx, K. (1968). Manuscritos económico-filosóficos de 1844. Trad. de Wenceslao Roces. México: Grijalbo.

Miller, D. (2001). Alienable gifts and inalienable commodities. En Myers, F. (Ed.), The empire of things: Regimes of value and material culture (pp. 91-115). Santa Fe: School of American Research Press.

Mitrovic, M. (2019). Extravíos de la forma: Vanguardia, modernismo popular y arte contemporáneo en Lima desde los 60. Lima: Pontificia Universidad Católica del Perú.

Moulin, R. (2012). El mercado del arte: Mundialización y nuevas tecnologías. Buenos Aires: La Marca Editora.

Paredes Laos, J. (2017). Miguel Aguirre: "El mercado artístico local está casi paralizado". El Dominical, 3 diciembre. Recuperado de https://elcomercio.pe/eldominical/entrevista-miguel-aguirre-mercadoartistico-local-paralizado-noticia-478335.

Parodi Trece, C. (2013). Crisis económica mundial e impacto sobre el Perú. Los Andes, 25 agosto. Recuperado de http://www. losandes.com.pe/oweb/Economia/20130825/74217.html.

Price, S. (2001 [1989]). Primitive art in civilized places, $2^{\mathrm{a}}$ ed. Chicago y Londres: The University of Chicago Press.

Roncaglia, A. (2016). Breve historia del pensamiento económico. Zaragoza: Prensas de la Universidad de Zaragoza.

Semana Económica (2014). Arte inversión: Cómo invertir en arte contemporáneo en el Perú. Lima: Semana Económica, SURA

Turner, T. (2008). Marxian value theory: An anthropological perspective. Anthropological Theory, 8(1), 43-56.

Valle, A. del \& Villacorta, J. (1997). Instituciones en las fronteras: Plástica en Lima en 1997. Cuestión de Estado, 21, 62-65.

Villacorta, J. \& Hernández-Calvo, M. (2002). Franquicias imaginarias: Las opciones estéticas de las artes plásticas en el Perú de fin de siglo. Lima: Pontificia Universidad Católica del Perú. 